\title{
Involvement of Auditory Cortical and Hippocampal Neurons in Auditory Working Memory and Reference Memory in the Rat
}

\author{
Yoshio Sakurai \\ Department of Psychology, Toyama Medical and Pharmaceutical University, Toyama 930-01, Japan
}

The goal of the present study was to see whether one neuron is involved exclusively in one type of memory or in different types of memory. Single-unit activity was recorded from rat hippocampal CA1, CA3, dentate gyrus, and auditory cortex (AC) during performances of auditory working memory (WM) and reference memory (RM) tasks. Both the memory tasks employed identical apparatus and stimuli and differed only in the type of memory required for correct performance.

Around $10 \%$ and $43 \%$ of the units from the four brain regions showed sensory correlates (differences in activity due to the type of sensory stimulus) only in the WM or RM task, respectively. Only the AC had units showing different kinds of sensory correlates between the WM and RM tasks. About $30 \%$ of the units from the four regions had sensoryretention correlates (sustained differential activity during the delay) only in the RM task, whereas the AC had units with sensory-retention correlates only in the WM task or in both the WM and RM tasks. Approximately $35 \%$ of the units from the hippocampal regions showed motor correlates (increments of activity immediately prior to responses) only in the WM task. Another $30 \%$ of the hippocampal units showed such correlates both in the WM and RM tasks. About $22 \%$ of the hippocampal CA1 and CA3 units showed comparisonmotor correlates (increases of activity prior to correct responses) only in the WM task.

These results indicate that some neurons are involved solely in WM or RM, whereas other neurons are involved in both WM and RM. The results also suggest that more neurons are involved in sensory and retention processing for RM than for WM, and that the $A C$ alone has flexible neurons involved in the processes for both types of memory. More hippocampal neurons are involved in the motor and comparison processes for WM than for RM.

[Key words: working memory, reference memory, auditory cortex, hippocampus, single neuron, cell assembly, rat]

Memory is classified into several types, each of which is thought to have a different subsystem in the brain (e.g., Squire, 1987). With regard to the neuronal mechanisms underlying the various types of memory, one of the principal questions is whether each

\footnotetext{
Received Mar. 29, 1993; revised Aug. 25, 1993; accepted Oct. 14, 1993.

This work was supported by Grants-in-Aid for Scientific Research (C) (02610040 and 04610044) and that on Priority Areas on 'Higher-Order Brain Functions" $(02255208,03251213$, and 04246216$)$ and by the Brain Science Foundation.

Correspondence should be addressed to Yoshio Sakurai, Department of Psychology, Toyama Medical and Pharmaceutical University, 2630 Sugitani, Toyama 930-01, Japan.

Copyright (C) 1994 Society for Neuroscience $0270-6474 / 94 / 142606-18 \$ 05.00 / 0$
}

individual neuron is exclusively involved in one type of memory or more generally involved in several different types of memory. The former view regards the neuron as a processor dedicated to a given type of memory. This point of view is based on the single neuron doctrine (Barlow, 1972), which holds that behavioral functions are uniqucly and consistently encoded in the activity of individual neurons. The latter view is based on the theory of the "cell assembly" (Hebb, 1949), which is a set of coactive neurons that is involved in several types of memory. Neurons comprising cell assemblies are thought to be considerably overlapped, in the sense that a typical neuron belongs to many assemblies (Palm, 1982). Therefore, any single neuron underlies several different types of memory. The present study aimed to determine which of these views is correct.

The two different types of memory employed in the present study are working memory (WM) and reference memory (RM). WM associates an event with its temporal/personal context, whereas RM processes information independently of its temporal/personal context (Honig, 1978; Olton, 1986). This WM/ RM distinction is similar if not identical to the episodic/semantic distinction frequently made in relation to human memory (Tulving, 1972). Both of these types of memory arc considered to be higher cognitive forms of memory. This study also used auditory cues as to-be-remembered stimuli, because rats have good ability to discriminate and remember them (e.g., D'Amato and Salmon, 1982).

Regions in the brain from which neuronal activity was recorded are auditory cortex (AC) and hippocampal CA1, CA3, and dentate gyrus (DG). The $A C$ is a neocortical region in which auditory short-term or long-term memory is thought to be stored (Squire, 1987). Several experiments recording neuronal activity from the $\mathrm{AC}$ have shown that $\mathrm{AC}$ neurons play a role in the discrimination and retention of auditory stimuli for WM (Gottlieb et al., 1989; Sakurai, 1990b) and for RM (Vaadia et al., 1982). Weinberger and co-workers have shown the dynamic plasticity of AC neurons in relation to associative learning (e.g., Weinberger et al., 1990). Few experiments, however, have compared functions of AC neurons between WM and RM situations.

The hippocampus has of course long been regarded as one of the most crucial structures for memory (e.g., Squire, 1987; ChanPalay and Kohler, 1989). Experiments using brain lesions (e.g., Olton and Papas, 1979; Morris et al., 1986) or neuronal recording (Wible et al., 1986) have compared the functions of the hippocampus between WM and RM situations. In all of those studics, howcver, the to-bc-remembered stimuli, the tested animals and/or tested neurons were not identical between the WM and RM tasks.

The present experiment employed an experimental technique 
to compare directly the neuronal activity of identical neurons between the WM and RM situations, in which the apparatus, stimuli, and time parameters were identical and only the types of memory required differed (Sakurai, 1992a). The task for WM is an auditory version (Sakurai, 1987) of continuous nonmatching-to-sample (Pontecorvo, 1983). The rat makes go and no-go responses to indicate whether the presented tone is the same as (match) or different from (nonmatch) the tone on the immediately preceding trial. Remembering the stimulus with its temporal context is necessary. The task for RM is a continuous discrimination. The rat makes go responses on high-tone trials and no-go responses on low-tone trials throughout a session. The temporal context of the to-be-remembered stimulus is not necessary. By alternating the training in these tasks, the rat comes to perform well in both tasks in $1 \mathrm{~d}$ (Sakurai, 1992a). The rat can know which task is employed in a given session only from its own response-reward contingency in early trials of each session. The tasks differ from one another only in the types of memory required, so any differences in neuronal activity between the tasks should be due to differences in the type of memory being utilized.

Both of the memory tasks are composed of discrete components, each of which involves a different psychological process. Consequently, the stimulus and behavioral correlates of unit activity can indicate the task components that are responsible for activation of the units (Sakurai, 1990a,b). Of particular interest are the following five topics, each of which constitutes a separate category of task-related unit activity. A sensory correlate is activity differentially related to an external stimulus relevant for correct responses. Units that encode information about the discriminative stimulus should have sensory correlates. A sensory-retention correlate is sustained activity during the delay immediately following a particular discriminative stimulus. Units that encode information about the discriminative stimulus and also retain that information even when the stimulus is removed should have sensory-retention correlates. A motor correlate is activity associated with a behavioral response. Units that influence responding should have motor correlates. A comparison-motor correlate is activity associated with specifically correct behavioral responses. Units that compare information from the memory with the stimulus on the current trial in order to carry out correct responses should have comparison-motor correlates. A multiple correlate is activity associated with the presence of the two kinds of task variables, the sensory-related (sensory and sensory-retention correlates) and the motor-related (motor and comparison-motor correlates) ones. Units with multiple correlates are involved in the conjunction of sensory and motor dimensions of the memory tasks.

Preliminary data using this paradigm have been reported elsewhere (Sakurai, 1992b).

\section{Materials and Methods}

\section{Subjects}

A total of nineteen 5-month-old male albino rats (Sankyo Labs, Toyama, Japan) were used. The rats were individually housed, with a $12: 12 \mathrm{hr}$ light/dark cycle. Cage dimensions were $25 \times 15 \times 20 \mathrm{~cm}$. Lights were on from 9:00 A.M. to 9:00 P.M. All behavioral training and recording was conducted during the light phase of the cycle. All rats were fed enough lab chow 1-3 hr after their daily training or recording session to maintain them at $90 \%$ of their ad libitum weight. Water was available continuously.

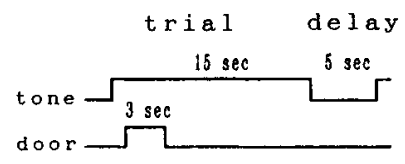

WORKING MEMORY

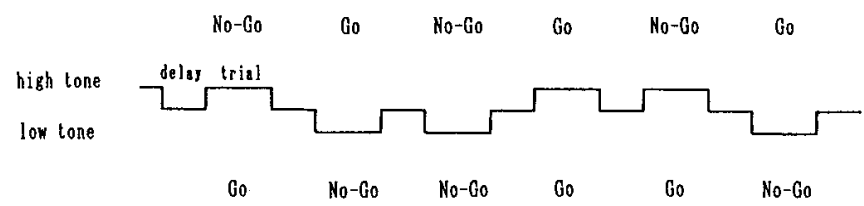

REFERENCE MEMORY

Figure 1. Top, Sequence of events within a single continuous trial and delay. Each trial consisted of a $15 \mathrm{sec}$ tone presentation and a $3 \mathrm{sec}$ response-opportunity period during which the panel was available to be pressed. The response-opportunity period started $1 \mathrm{sec}$ after the start of the tone presentation of each trial. Bottom, Typical sequence of trials, delays, and responses within a session of WM and RM tasks.

\section{Apparatus}

Behavioral training took place in an operant chamber, $23 \times 11 \times 35$ $\mathrm{cm}$ (Sakurai, 1987). One wall of the chamber had a translucent response panel, $4 \times 7 \mathrm{~cm}, 3 \mathrm{~cm}$ above the floor. The panel could be illuminated by an $8 \mathrm{~V}$, direct-current bulb and could be covered by a guillotine door. A buzzer was located behind the panel, and a loudspeaker, $15 \mathrm{~cm}$ in diameter, was set $30 \mathrm{~cm}$ above the top of the chamber. A food dispenser delivered a $45 \mathrm{mg}$ food pellet to a magazine that was located $1.5 \mathrm{~cm}$ above the floor and $1 \mathrm{~cm}$ from the corner of the right wall. The chamber was enclosed in a soundproof box (Japan Shield Enclosure, Osaka, Japan). All events were controlled and the behavioral and neuronal data recorded by personal computers (NEC, Tokyo, Japan).

\section{Behavioral training}

A description of the training procedure and some behavioral data have been given elsewhere (Sakurai, 1992a). At the start of each trial, one of two tones was presented and continued for $15 \mathrm{sec}$. One second after tone onset, the guillotine door opened to make the illuminated response panel available for $3 \mathrm{sec}$. Pressing the panel during the $3 \mathrm{sec}$ period was a go response and not pressing it for the $3 \mathrm{sec}$ was a no-go response. A variable number of high-tone $(10 \mathrm{kHz}, 85 \mathrm{~dB}$ SPL above a reference of $\left.20 \mu \mathrm{N} / \mathrm{m}^{2}\right)$ trials alternated with a variable number of low-tone $(2 \mathrm{kHz}$, $85 \mathrm{~dB}$ ) trials. The delay period (intertrial interval) between trials was 5 sec. A training session consisted of 150 trials. Each session had 75 hightone trials and 75 low-tone trials. There were 50 nonmatch trials, in each of which a stimulus different from the preceding trial was presented, and 100 match trials, in each of which a stimulus identical to that of the preceding trial was presented. A median of three match trials occurred between successive nonmatch trials (range $=1-5$ ).

WM task. The WM task is an auditory continuous nonmatching-tosample. The rat was required to make go responses on nonmatch trials and no-go responses on match trials. A go response on a nonmatch trial turned the panel light off and delivered a food pellet immediately after the response. A nonmatch trial was always followed by a match trial $(\mathrm{NM}+1$ trial), from which data were not obtained (Sakurai, 1990a,b). A go response on a match trial turned the panel light off, produced a $0.5 \mathrm{sec}$ buzzer noise, and was followed by two further match trials (correction trials) on which no-go responses were required. Data were not obtained from the correction trials. The rat had to remember, during the delay, which stimulus had been presented most recently. In other words, remembering a stimulus with its temporal context was necessary.

$R M$ task. The RM task is a continuous discrimination. The rat was required to make go responses on high-tone trials and no-go responses 
Figure 2. Anatomical locations of the tips of the cannula rows, each of which consisted of five cannulas with electrodes. The numbers beside each section indicate the distance from bregma. (constructed from Paxinos and Watson, 1986; reprinted by permission.)

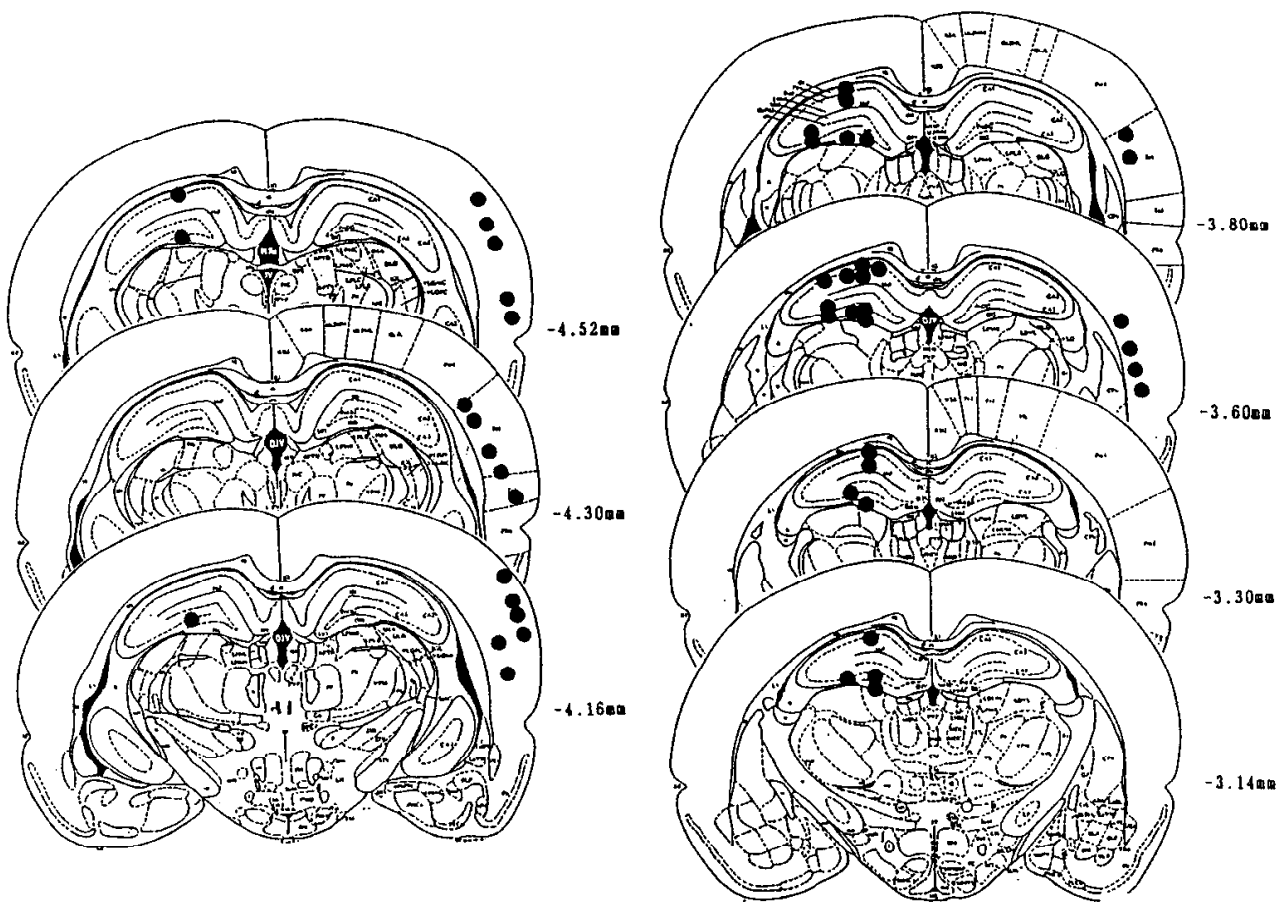

puncturing the exposed dura matter, the electrode tips were implanted to a depth of about $500 \mu \mathrm{m}$ into the cortex. The craniotomy was filled with Dow Corning silicone to a level just above the exit of the electrode from the cannula. After coating the supports of the microdrive and cannulas with a thin film of Dow Corning silicone, the entire assembly was embedded in dental cement.

\section{Unit recording and analysis}

Six days after the surgery, the implanted electrodes were lowered into the brain using the microdrive to detect unit activity. An electrode pair was led to a field-effect transistor (FET) module mounted on the head. The FET module consisted of five FETs (Toshiba, Tokyo, Japan) to which the five electrode pairs were led. Single units from five electrode pairs could therefore be recorded simultaneously. About two to four units were usually recorded at one recording time. Their outputs were further amplified and then fed into time-amplitude window discriminators (BAK Electronics, Germantown, MD) to change the unit activity into a discrete TTL rectangular pulse. A TTL I/O board in the computer system counted the TTL pulses. The activity of a unit was recorded as a single unit if it had a peak amplitude more than 2.0 times greater than noise, and the amplitude, duration (spike width), and waveform were confirmed to be constant by visual examination on a storage oscilloscope. This method of differential recording has been shown to yield stable single unit activity (Sasaki et al., 1983; McNaughton et al., 1989). In the cases in which one electrode had multiple units, single units were identified and recorded by means of separation with the time-amplitude window discriminator.

Recording during the performance of the tasks. When unit activity was detected, the rat was returned to its home cage. When the unit activity was still present on the next day, around $15 \mathrm{hr}$ after the detection of the unit, it was judged to be stable for several hours of recording. The rat was then retrained in the WM and RM tasks in that order and single units were recorded during the task performances. A recording session consisted of 120 or 150 trials, which lasted about $1 \mathrm{hr}$, and the interval between the WM and the RM tasks was around $1.5 \mathrm{hr}$. Consequently, a recording period for the unit activity was about $3.5-4.5 \mathrm{hr}$, during which changes in the recording quality were unlikely to occur. Recorded unit activity was stored in a computer memory and histograms of firing rate were tabulated. Because it is usually difficult to predict a type (normal or non-normal) of distribution of neuronal firing rates and populations of task-related units, distribution-free nonparametric statistics ( $U$ test and $\chi^{2}$ test; Siegel, 1956) were used to analyze the unit activities statistically to define task-related activities.

Recording spontaneous and stimulus-elicited activity not during the memory tasks. After recording unit activity during the performance of $\mathrm{mm}$ lateral from the midline; $\mathrm{CA} 1$ and $\mathrm{DG}, 4.0 \mathrm{~mm}$ posterior from bregma and $2.5 \mathrm{~mm}$ lateral from the midline; CAl and CA3, $4.0 \mathrm{~mm}$ posterior from bregma and $3.2 \mathrm{~mm}$ lateral from the midline. After 
UNIT 20-2W1 Cel1 2
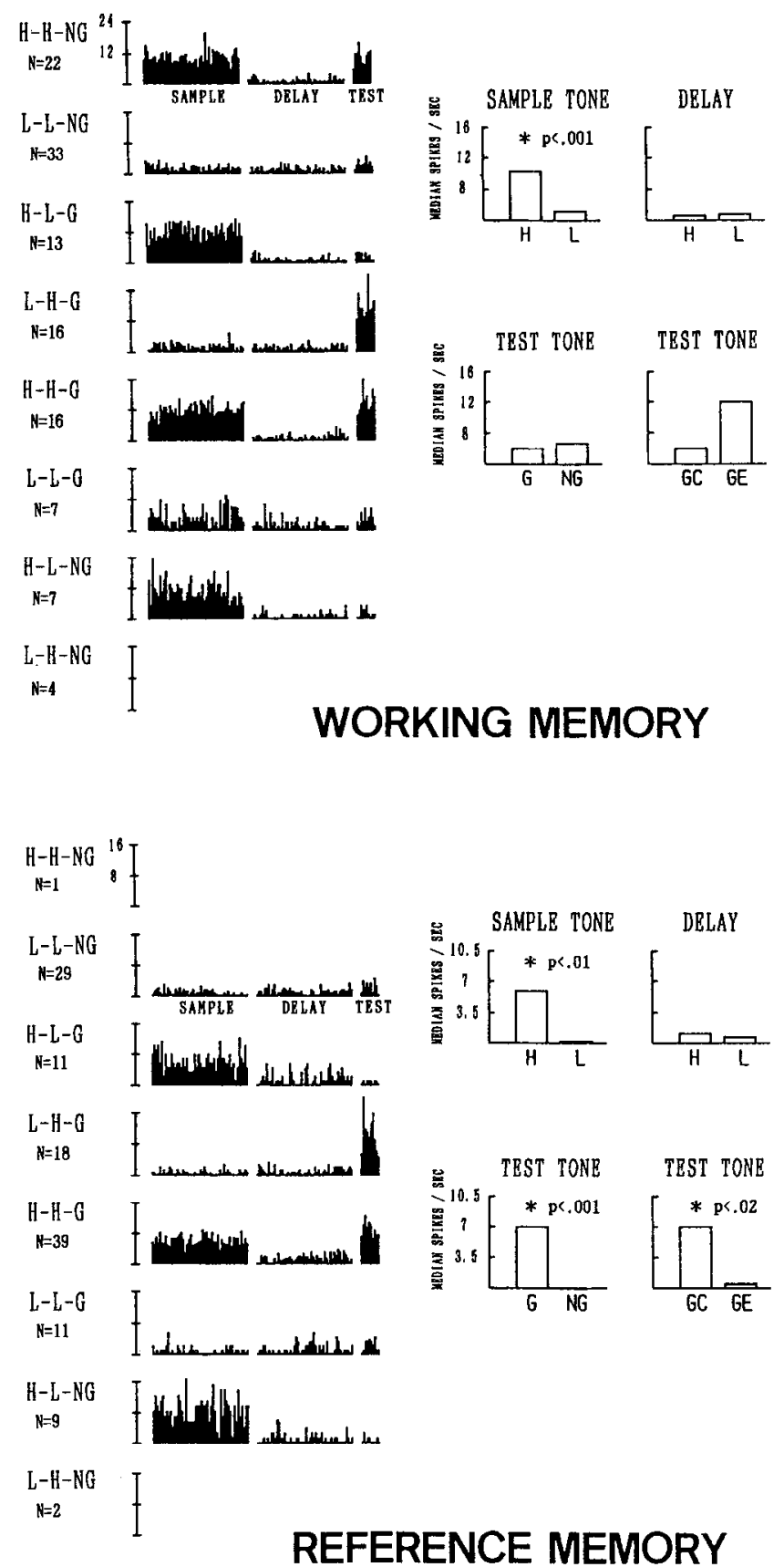

REFERENCE MEMORY

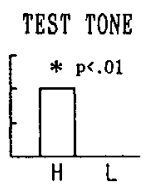

TEST TONE

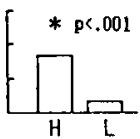

Figure 3. Firing rate histograms (left) and bar graphs for statistical analysis (right) from an $\mathrm{AC}$ unit during the performance of WM (top) and RM (bottom) tasks. The histogram represents firing rates during sample tone $(5 \mathrm{sec})$, delay ( $5 \mathrm{sec}$ ), and test tone (1 sec). Eight types of histograms were obtained from each unit. Each type of trial is identified with an abbreviation that indicates, in order, the tone on the previous and the presented trials ( $H$, high; $L$, low) and the response conducted next ( $G$, go; $N G$, no-go). Because the rats rarely made some types of errors (e.g., no-go responses on nonmatch trials in the WM task and no-go responses on high-tone trials in the RM task), histograms from those small numbers of trials are not shown. Histograms from the types of trials, in which fewer than five trials were collected, are also not presented. Binwidth is $100 \mathrm{msec} ; N=$ number of trials collected. Bar graphs on the right represent median firing rates during sample tone, delay, and test tone of the same unit presented in the histograms. $H$, high tone was simultaneously presented (SAMPLE TONE and TEST $T O N E$ ) or was presented immediately before $(D E L A Y) ; L$, low tone was simultaneously presented (SAMPLE TONE and TEST TONE) or was presented immediately before (DELAY); $G$, go response was made during the trial; $N G$, no-go response was made during the trial; $G C$, correct go response was made during the trial; $G E$. erroneous go response was made during the trial. The trials analyzed are those on which the rat made correct responses, except the trials of GE. Note that the comparison during the test tone between high and low tones and that between go and no-go responses in the RM task are identical, because the correct go and no-go responses are conducted on the high-tone and low-tone presented trials, respectively. ${ }^{*}$, a statistically significant difference ( $U$ test) between the pair of bar graphs. The bottom right part (OUT OF TASK) of this figure shows median spontaneous (spon.) and stimulus-elicited (1-20 kHz) firing rates of the unit at a time when there was no memory task. 9 , a frequency of the tone used in the memory tasks. *, a statistically significant difference ( $U$ test) between the spontaneous and stimulus-elicited firing rates. the tasks, the response panel was covered with a board and spontaneous activity of the unit was recorded for $1 \mathrm{~min}$ when the rat was alert but quiet. Recording was also carried out during the presentation of 20 auditory tones with different frequencies $(1-20 \mathrm{kHz})$ for $1 \mathrm{sec}$ each in random order. Tones of each frequency were presented 20 times with an intertone interval of $1 \mathrm{sec}$. Stimulus-elicited activation of units for each frequency of tone was detected by a statistical comparison ( $U$ tcst) between spontaneous activity and activation during the auditory stimulation.

\section{Histology}

After the experiment, each rat was deeply anesthetized with an overdose of sodium pentobarbital $(120 \mathrm{mg} / \mathrm{kg})$, and perfused with $10 \%$ buffered formalin solution. The brain was frozen, sectioned at $50 \mu \mathrm{m}$ intervals, and stained with cresyl violet. The locations of electrode tips and tracks in the brain were identified with the aid of a stereotaxic atlas (Paxinos and Watson, 1986).

\section{Results}

Record samples

Figure 2 shows the anatomical locations of the tips of the cannulas with electrodes. The total number of recorded units was 172, of which 54 were from AC, 41 were from CA1, 34 were from $\mathrm{CA} 3$, and 43 were from DG. The units from CAl and 


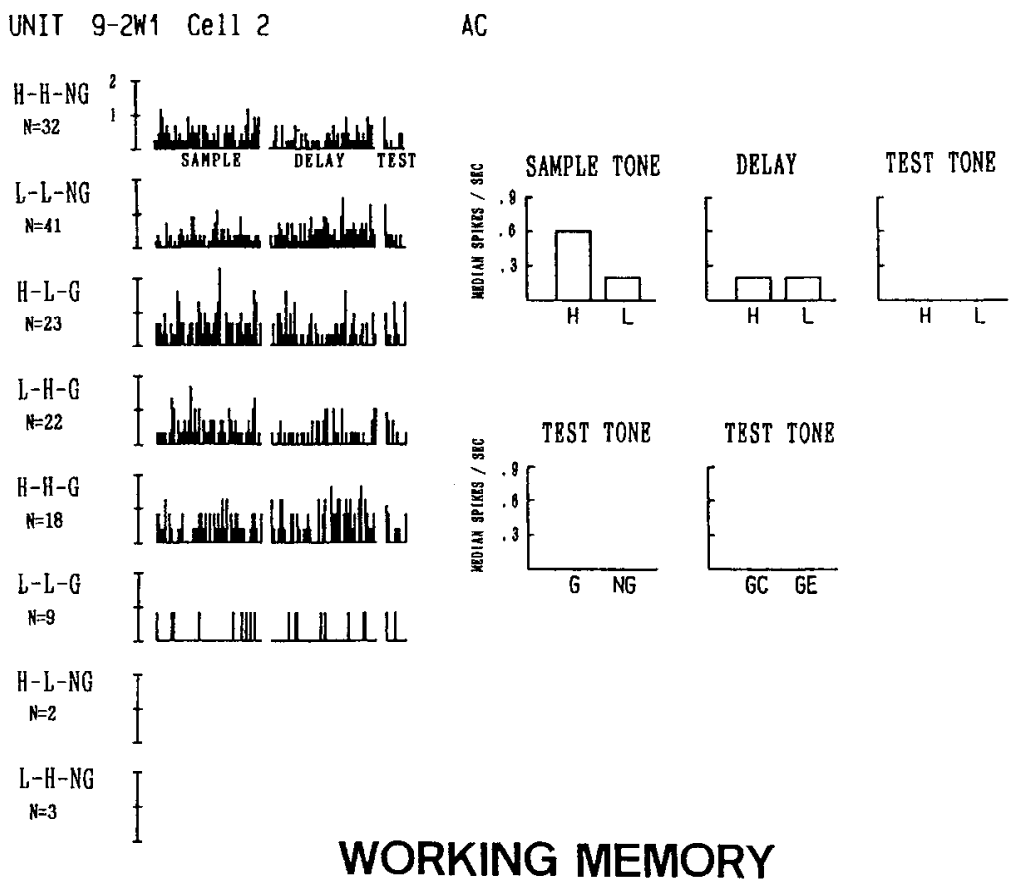

Figure 4. Firing rate histograms and
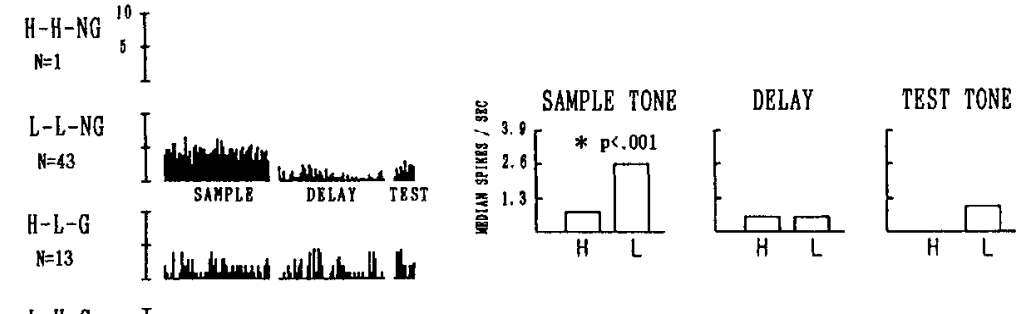

bar graphs from an $\mathrm{AC}$ unit showing a sensory correlate only in the RM task. All parameters and symbols are as in Figure 3.
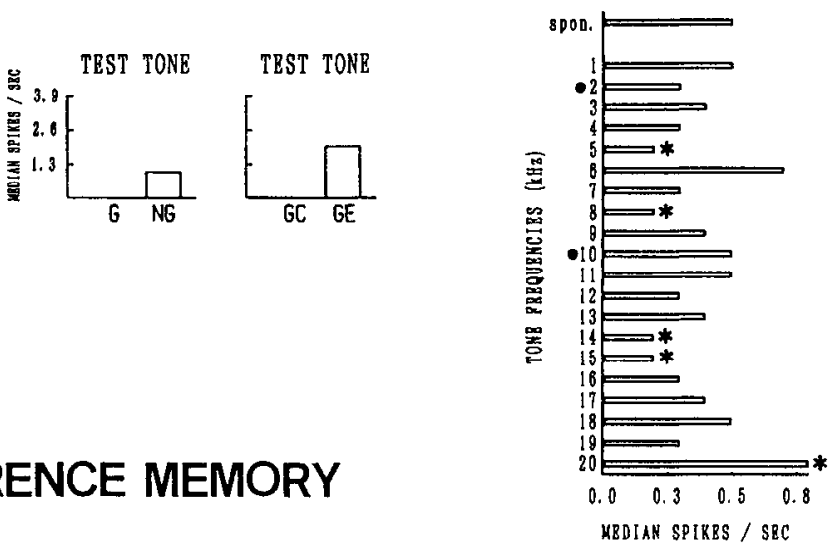

REFERENCE MEMORY

OUT OP TASR

CA3 were judged to be complex spike cells, because their spontaneous firing rates were low $(0.1-8 \mathrm{~Hz})$ and their spike durations were long (more than $0.5 \mathrm{msec}$ ) (Christian and Deadwyler, 1986; Foster et al., 1987); $\theta$ cells were not included.

\section{Perievent firing rate histograms}

Unit activity was analyzed in three temporal periods of the task: samplc tonc, dclay, and tcst tonc (Sakurai, 1990a,b). The sample tone was the last $5 \mathrm{sec}$ of the tone in a trial, the test tone was the first $1 \mathrm{sec}$ of the tone during the next trial (the period immediately prior to raising the door), and delay was the period between the sample tone and the test tone. Unit activity after raising the door was not analyzed. During these three temporal periods, the activity of each unit was classified by the type of tone (high or low) and the type of subsequent response (go or no-go). Eight types of perievent firing rate histograms based on this classification system could be obtained from each unit. Because the present memory tasks consisted of the continuous altcrnation between trial and delay periods, there were no baseline periods (i.e., intertrial intervals) that could be compared with the periods of trial and delay. Therefore, the data were statistically analyzed not by sequential comparison of pre- (base- 
UNIT 1-1W1 Cell 2
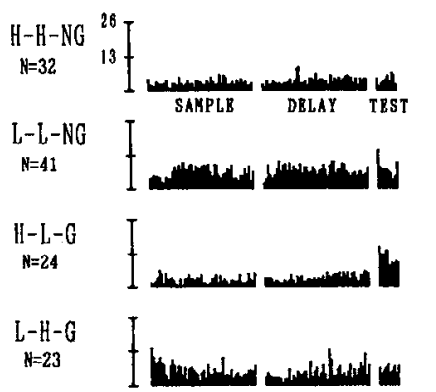

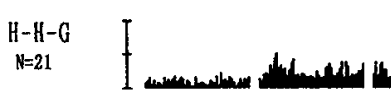

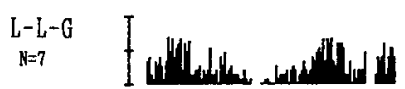

$\mathrm{H}-\mathrm{L}-\mathrm{NG}$

$N=1$

L-H-NG

$n=1$
$A C$
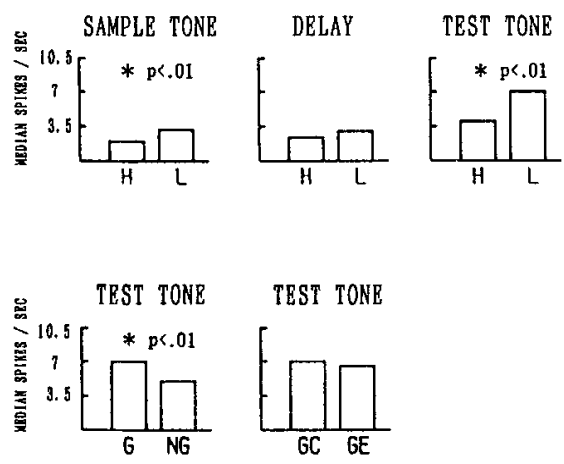

WORKING MEMORY
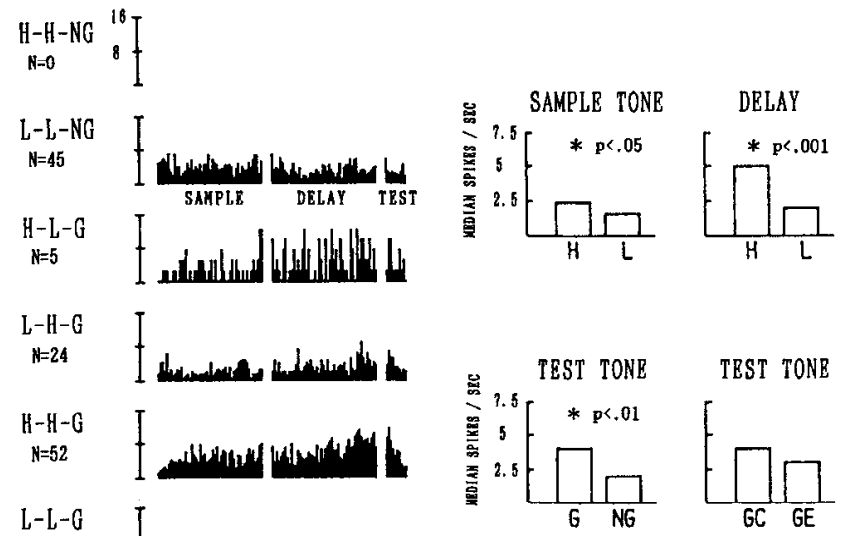

TEST TONB
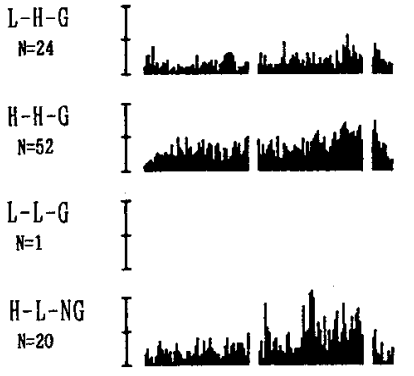

$\mathrm{L}-\mathrm{H}-\mathrm{NG}$

$\mathrm{N}=0$

\section{REFERENCE MEMORY}

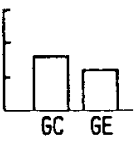

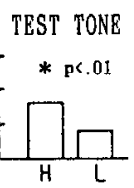

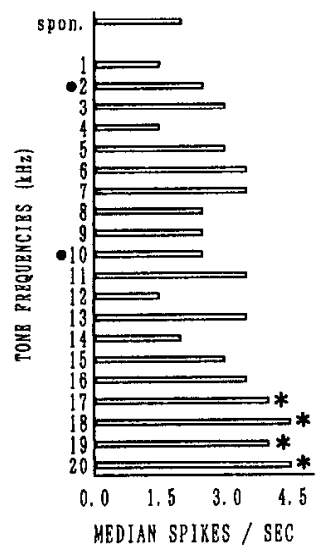

OUT OF TASK
Figure 5. Firing rate histograms and bar graphs from an $\mathrm{AC}$ unit showing different sensory correlates between the WM and RM tasks. All parameters and symbols are as in Figure 3. line) and postevent firing rate, but by comparison between the different types of histograms, which corresponded to different variables of stimulus and response.

Figure 3 is an example of the histograms and the statistical analysis obtained from a unit in $\mathrm{AC}$. The figure is divided into upper and lower portions, corresponding to when the rat was performing the WM and RM tasks, respectively. The firing rate histograms are shown on the left side.

The bar graphs in Figure 3 compare firing rates for the unit between periods when high tone and low tone were presented during the sample tone and the test tone, or presented immediately before the delay. The bar graphs also compare the firing rates during the test tone immediately before the rat made go or no-go responses and correct go or erroneous go responses.

\section{Sensory correlates of unit activity}

The AC unit in Figure 3 showed different activation during high and low tones during the sample and test tone periods both in 


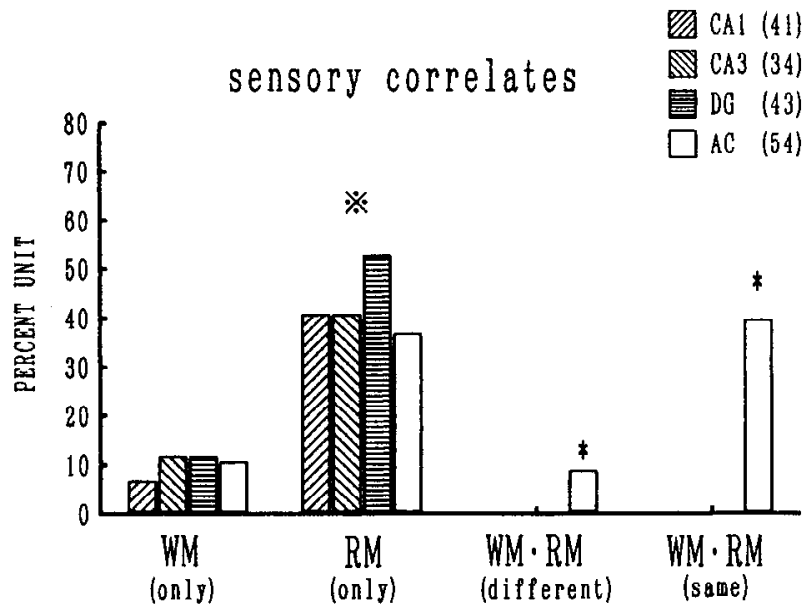

Figure 6. Proportions of the units with sensory correlates in the four regions. $W M(o n l y)$, units showing sensory corrclates only in the WM task; $R M$ (only), units showing sensory correlates only in the RM task. $W M \cdot R M$ (different), units showing different sensory correlates between the WM and RM tasks; WM.RM (same), units showing the same sensory correlates in the WM and RM tasks. $X$, a statistically significant difference ( $\chi^{2}$ test) among WM (only), RM (only), WM RM (different) and WM.RM (same); ${ }^{*}$, a statistically significant difference $\left(\chi^{2}\right.$ test) among the regions. Numbers in parentheses are the total units recorded.

the WM and RM tasks. Therefore, the activity of this unit correlated with the type of stimulus. The correlate observed in the histograms was confirmed statistically in the bar graphs in the right side of Figure 3 by a nonparametric $U$ test (Siegel, 1956). The bottom right part of Figure 3 shows data from the recording of spontaneous and stimulus-elicited activation out of the tasks (see Unit recording and analysis in Materials and Methods). The unit showed stimulus-elicited activation that differed between high and low tones during the memory tasks. Therefore, the differential activity of this unit during the memory tasks is thought to reflect not simple sensory but task-related mnemonic functions. This type of unit had what is referred to as a sensory correlate both in the WM and RM situations, and played a role in sensory discrimination for both WM and RM. Units that showed similar differential stimulus-elicited activation out of the tasks were not included in the analysis of the units with sensory correlates.

Some units had sensory correlates only in one of the memory tasks. Figure 4 shows an example of units from AC, which had a sensory correlate only in the RM task. That is, the activity of this unit during the sample tone was different between high and low tones in the RM task. This unit played a role in sensory discrimination only for RM. Activity during the test tone in the RM task might reflect not only sensory but also motor functions, because go responses are conducted on high-tone presented trials. Therefore, the sensory correlate in the RM task is classified by its differential activity during the sample tone.

Some units had sensory correlates that were different between the WM and RM tasks. The unit from AC shown in Figure 5 had sensory correlates in both WM and RM tasks, and the types of differential activation were different between the tasks. That is, in the WM task, the activity of this unit during the low-tone sample and the test tones was greater than that during the hightones ones. In the RM task, the activity during the high-tone sample and test tones was greater than that during the low-tones ones. This unit had a flexible role in sensory discrimination for both WM and RM.
The locations of the units with sensory correlates were almost randomly distributed in each of the four regions. Concerning the $\mathrm{AC}$, the distribution of units with sensory correlates was not related to the functional anatomy or known subdivisions in AC (e.g., Sally and Kelly, 1988).

\section{Proportions of units with sensory correlates}

Figure 6 shows the proportions of the units with sensory correlates in each of the four regions. The correlates were classified into four types: sensory correlates only in the WM task, only in the RM task (e.g., Fig. 4), in both the WM and the RM tasks in different fashions (e.g., Fig. 5), and in both WM and RM tasks in the same fashion (e.g., Fig. 3).

All of the regions had units with sensory correlates only in the WM or the RM task, and there were no statistical differences among the regions. The RM task had many more units (around $40 \%$ ) with sensory correlates than the WM task (around 10\%) (between the correlate types: $\chi^{2}(1)=11.46, p<0.001$ ). The AC alone had units with different sensory correlates for the WM and the RM tasks (among the regions: $\chi^{2}(3)=15.86, p<0.005$ ). The AC alone also had many units with the same and common sensory correlates in both the WM and the RM tasks (among the regions: $\left.\chi^{2}(3)=56.16, p<0.001\right)$. Concerning the proportion of units with high- and low-tone preferred activation, there was no systematic difference between the tasks.

\section{Sensory-retention correlates of unit activity}

Some of the units with sensory correlates showed sustained differential activity during the delay periods for retention immediately after presentation of the sample stimulus. This sustained activity is referred to as a sensory-retention correlate. The differential activity in the RM task in Figure 5 shows an example of this correlate. The unit from AC in Figure 7 had sensory-retention correlates both in the WM and in the RM tasks. That is, the activity of this unit during the sample tone, delay, and test tone was different between high and low tones in the WM and RM tasks. In order to make sure that the differential activity was sustained throughout the delay period, the activity of each unit with a sensory-retention correlate was compared again during the first and the second halves of the delay period (see the bottom right bar graphs of the upper and lower portions of Fig. 7). Units that showed differential activity during both periods were judged to be units with sensory-retention correlates (Sakurai, 1990b). The unit in Figure 7 is thought to be involved in sensory discrimination and retention for both WM and RM.

The unit from CA3 in Figure 8 had a sensory-retention correlate only in the RM task. That is, the activity of this unit during the sample tone, delay, and test tone was different between high and low tones in the RM task. This unit was related to sensory discrimination and retention only for RM.

\section{Proportions of units with sensory-retention correlates}

Figure 9 shows the proportions of units with sensory-retention correlates in each of the regions. Note that the units with sensory correlates in Figure 6 included the units with sensory-retention correlates in Figure 9. The sensory-retention correlates were classified into four types in the same manner as in Figure 6.

The AC alone had some units with sensory-retention correlates only in the WM task (among the regions: $\chi^{2}(3)=9.25, p$ $<0.05)$. Many more units had sensory-retention correlates only in the RM task (e.g., Fig. 8) than had sensory-retention correlates 

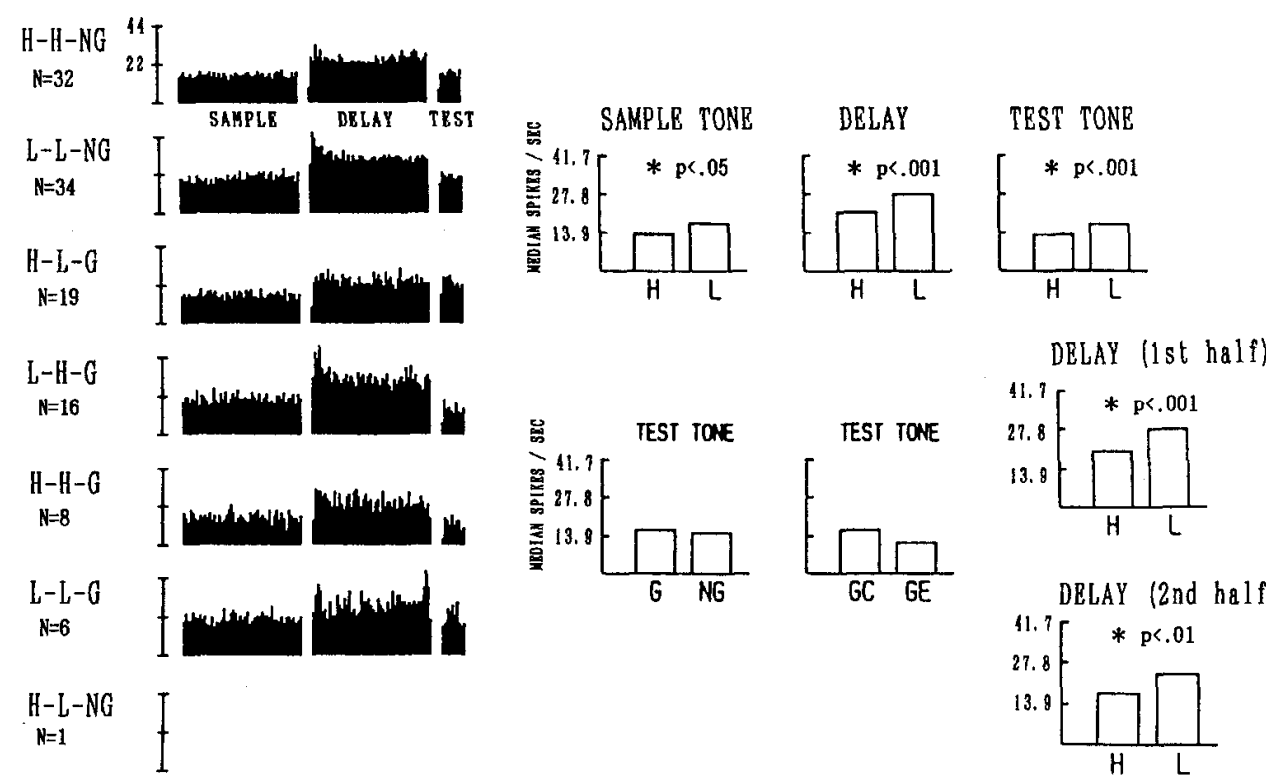

$\underset{N=4}{L-H-N G}+$

\section{WORKING MEMORY}

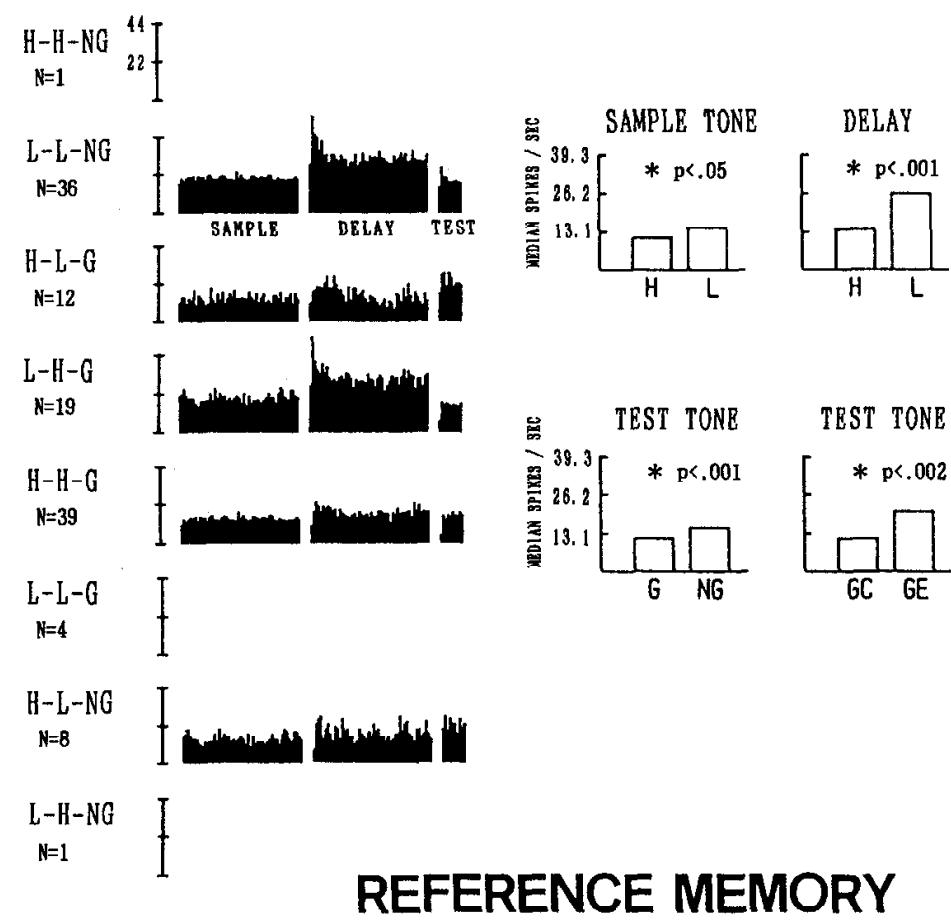

TEST TONE

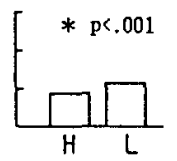

DELAY (1st half)

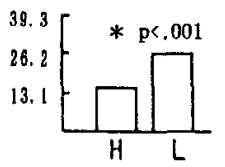

DELAY (2nd half)

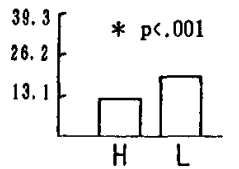

Figure 7. Firing rate histograms and bar graphs from an AC unit showing sensory-retention correlates both in the WM and the RM tasks. The bar graphs also represent median firing rates during the first and second halves of delay in the WM and RM tasks. All parameters and symbols are as in Figure 3. only in the WM task or in both the WM and RM tasks (among the correlate types: $\left.\chi^{2}(2)=22.2, p<0.001\right)$. Comparison of Figures 6 and 9 shows that most of the units with sensory correlates only in the RM task were the units with sensory-retention correlates. No units had different sensory-retention correlates between the WM and RM tasks. The AC alone had some units with the same and common sensory-retention correlates both in the WM and in the RM tasks (e.g., Fig. 7) (among the regions: $\left.\chi^{2}(3)=15.47, p<0.05\right)$. The AC played a role in sensory discrimination and retention for both WM and RM.

Motor correlates of unit activity

Units that showed differential activation between the time of the test tone prior to go responses and that prior to no-go re- 

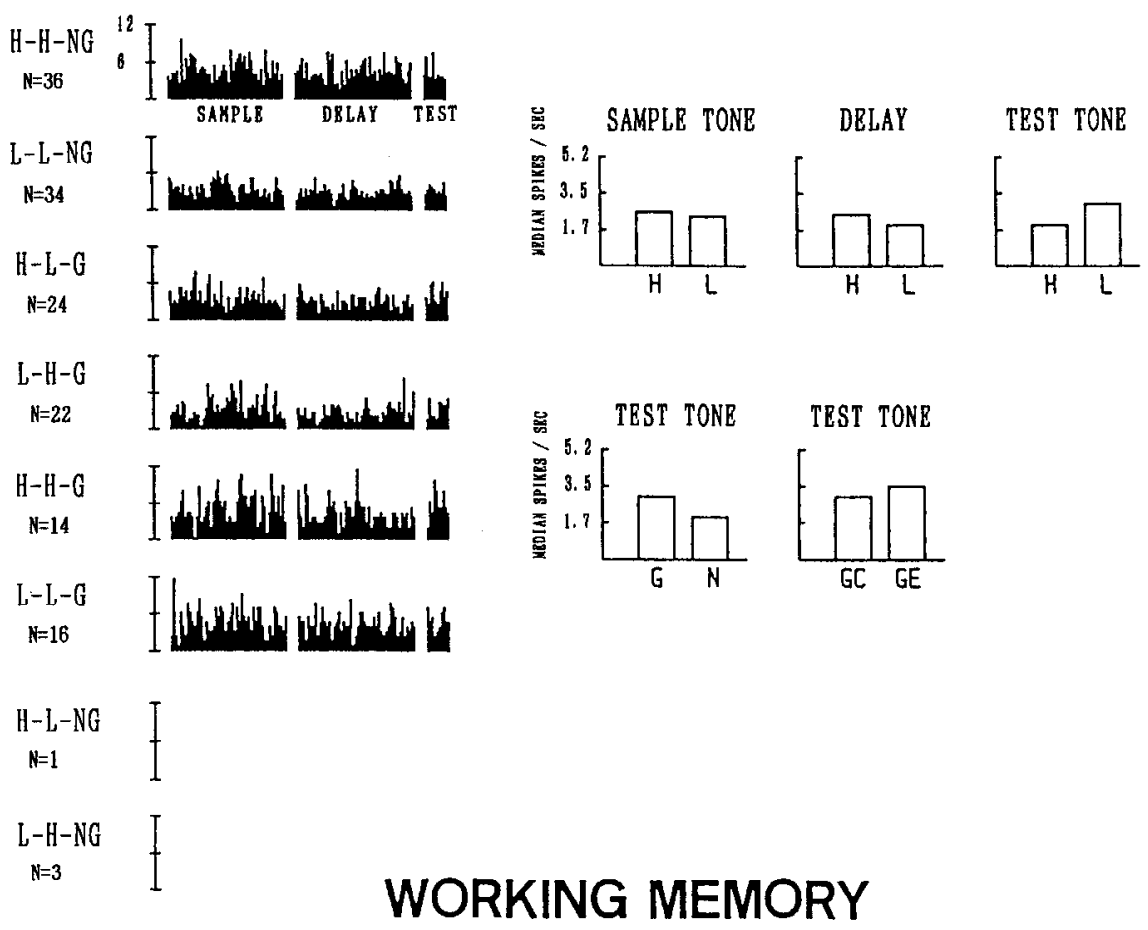

Figure 8. Firing rate histograms and bar graphs from a CA3 unit showing a sensory-retention correlate only in the RM task. The bar graphs also represent median firing rates during the first and second halves of delay in the RM task. All parameters and symbols are as in Figure 3.
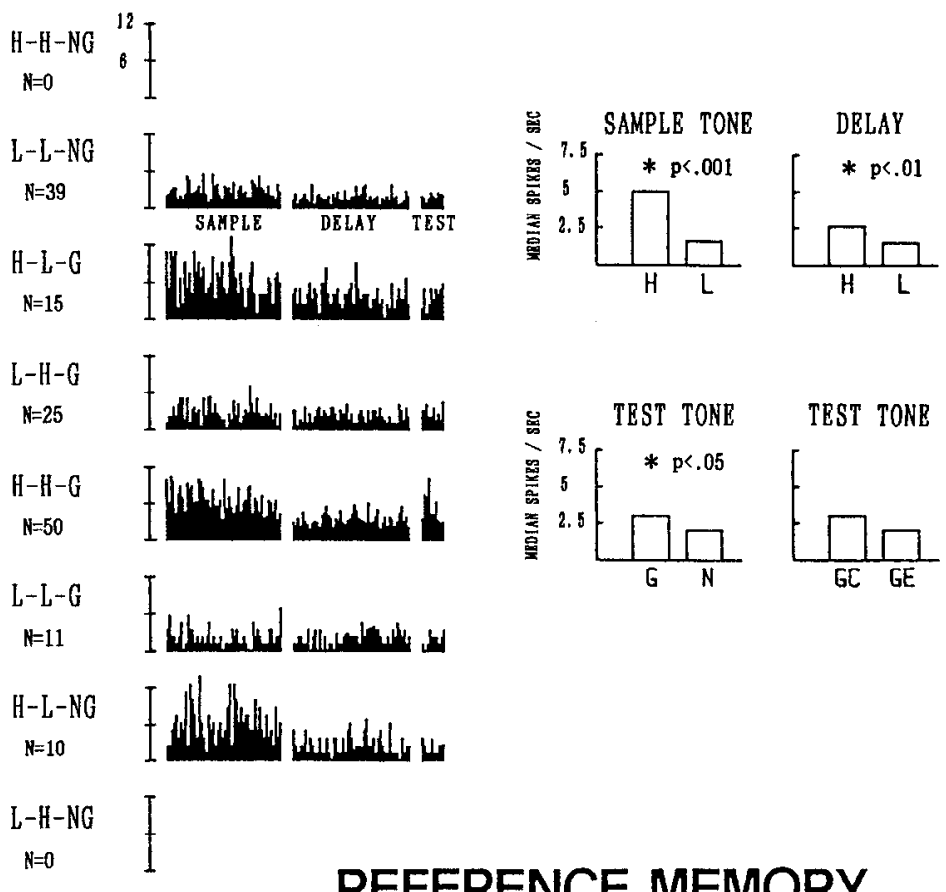

TEST TONE
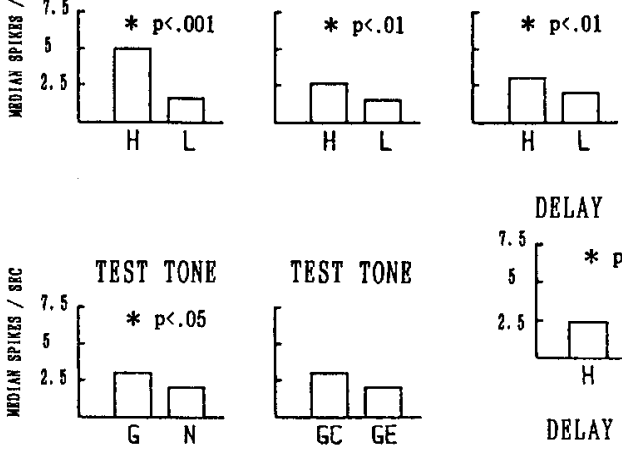

DELAY (1st half)

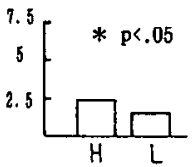

DELAY (2nd half)

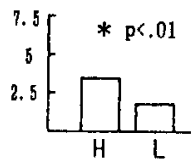

\section{REFERENCE MEMORY}

sponses had motor correlates. Figure 10 shows a unit from $\mathrm{CA} 1$ with motor correlates. The activity during the test tone increased prior to go responses both in the WM and in the RM tasks. Therefore, it is concluded that this unit played a role in motor control for both WM and RM.

The unit from CA3 in Figure 11 had a motor correlate only in the WM task. The activity of this unit during the test tone was different between go and no-go responses in the WM task. This unit was involved in motor control only for WM.

\section{Proportions of units with motor correlates}

The proportions of units with motor correlates in each region are shown in Figure 12. The motor correlates were classified into four types in the same manner as in Figures 6 and 9. A 
different motor correlate would mean a unit that showed an increment of activity prior to go responses in one of the memory tasks and prior to no-go responses in the other memory task, but no units with such different motor correlates were found. The motor correlates of the units in Figure 12 were increments of activity prior to go responses.

The hippocampal CA1, CA3, and DG had more units with motor correlates only in the WM task (e.g., Fig. 11) (among the regions: $\left.\chi^{2}(3)=12.99, p<0.005\right)$ and both in the WM and in the RM tasks (e.g., Fig. 10) (among the regions: $\chi^{2}(3)=9.52, p$ $<0.025)$ than the AC had. Proportions of the units with motor correlates only in the RM task were smaller than those only in the WM task and those both in the WM and in the RM tasks (among the correlate types: $\chi^{2}(2)=6.08, p<0.05$ ). Therefore, some of the units in the hippocampal CA1, CA3, and DG had a role for motor control only for WM. Also some of the units in the hippocampal regions had a role in motor control for both WM and RM.

\section{Comparison-motor correlates of unit activity}

Though the rats rarely made erroneous no-go responses, the go responses could be divided into correct and erroneous responses. Consequently, the activity of each unit with a motor correlate was also compared during the test tone prior to correct go responses and prior to erroneous go responses. A unit for which this analysis showed differential activity is referred to as having a comparison-motor correlate, because the correct and erroneous trials had the same stimuli and responses and differed only in the correctness of the comparison of the current stimulus and the retained memory (Sakurai, 1990a).

The unit from CA3 in Figure 13 had a comparison-motor correlate only in the WM situation. The activity during the test tone increased only prior to the correct go responses. This unit was involved in the comparison process of the presented stimulus and the sustained WM and in the motor control needed to emit the correct response.

\section{Proportions of units with comparison-motor correlates}

Figure 14 presents the proportions of the units with comparisonmotor correlates in each region. The correlates were classified into the same four types, but there were no units with different or same comparison-motor correlates between the memory tasks. The hippocampal CA1 and CA3 had more units with the correlates only in the WM task (e.g., Fig. 13) than the DG and the $A C$ (among the regions: $\chi^{2}(3)=18.52, p<0.001$ ). The proportions were larger (almost significantly) than those of the units with the correlates only in the RM task (between the correlate types: $\left.\chi^{2}(1)=3.79, p<0.1\right)$. Therefore, it is concluded that the units from the hippocampal CA1 and CA 3 were more involved in comparison and motor processes only for WM.

\section{Multiple correlates of unit activity}

The sensory and sensory-retention correlates reflect sensoryrelated functions of the unit, whereas the motor and comparison-motor correlates reflect motor-related functions. Some units had both sensory-related and motor-related correlates in a memory task. Those are referred to as multiple correlates, because they indicate multiple functions for both sensory or sensoryretention processes and motor or comparison-motor processes. Figure 15 shows a unit from CA3 with multiple, sensory-retention and comparison-motor correlates only in the RM task. That

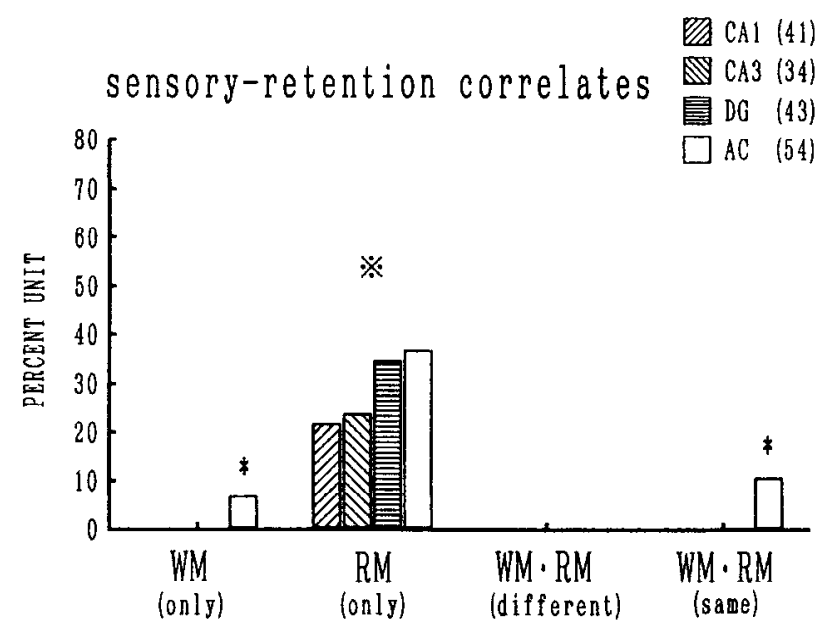

Figure 9. Proportions of the units with sensory-retention correlates in the four regions. All parameters and symbols are as in Figure 6.

is, the activity of this unit during the sample tone and delay was different between high and low tones in the RM task. Also, the activity during the test tone was different between correct go and erroneous go responses in the RM task. This unit had multiple functions, sensory discrimination, retention, comparison of the auditory stimulus and the retained memory, and motor control only for RM.

\section{Proportions of units with multiple correlates}

Figure 16 presents the proportions of the units with multiple correlates in each region. The correlates were classified into the same four types, but there was no unit with the same multiple correlates in both of the memory tasks. All of the regions had more units with multiple correlates only in the RM task (e.g., Fig. 15) than only in the WM task (between the correlate types: $\chi^{2}(1)=4.84, p<0.05$ ). Therefore, more units from all of the regions had multiple sensory and motor functions for RM than for WM.

The AC alone had units with different multiple correlates between the tasks (among the regions: $\chi^{2}(3)=16.26, p<0.05$ ). Therefore, it can be said that the AC contained more flexible units for multiple sensory and motor functions for both WM and RM.

Table 1 summarizes the proportions of units showing sensory, sensory-retention, motor, comparison-motor, and multiple correlates.

\section{Proportions of units responsive to tones not during the tasks}

Figure 17 summarizes the proportions of units that showed significantly large or small responses (compared with their spontaneous activities) to the tones $(1-20 \mathrm{kHz})$ presented at a time not during the memory tasks. The total proportions exceed $100 \%$ in each of the regions because some of the units responded to several frequencies of tone. There is no significant difference among the regions or among the frequencies in each of the regions. This indicates that there is no best or better frequencies for the recorded units and that the tones $(2 \mathrm{kHz}$ and $10 \mathrm{kHz})$ employed in the memory tasks had no spccific property for the units not during the memory tasks. There also is no systematic relationship between the tuning properties of the units not during the tasks and their activity correlates during the tasks. 


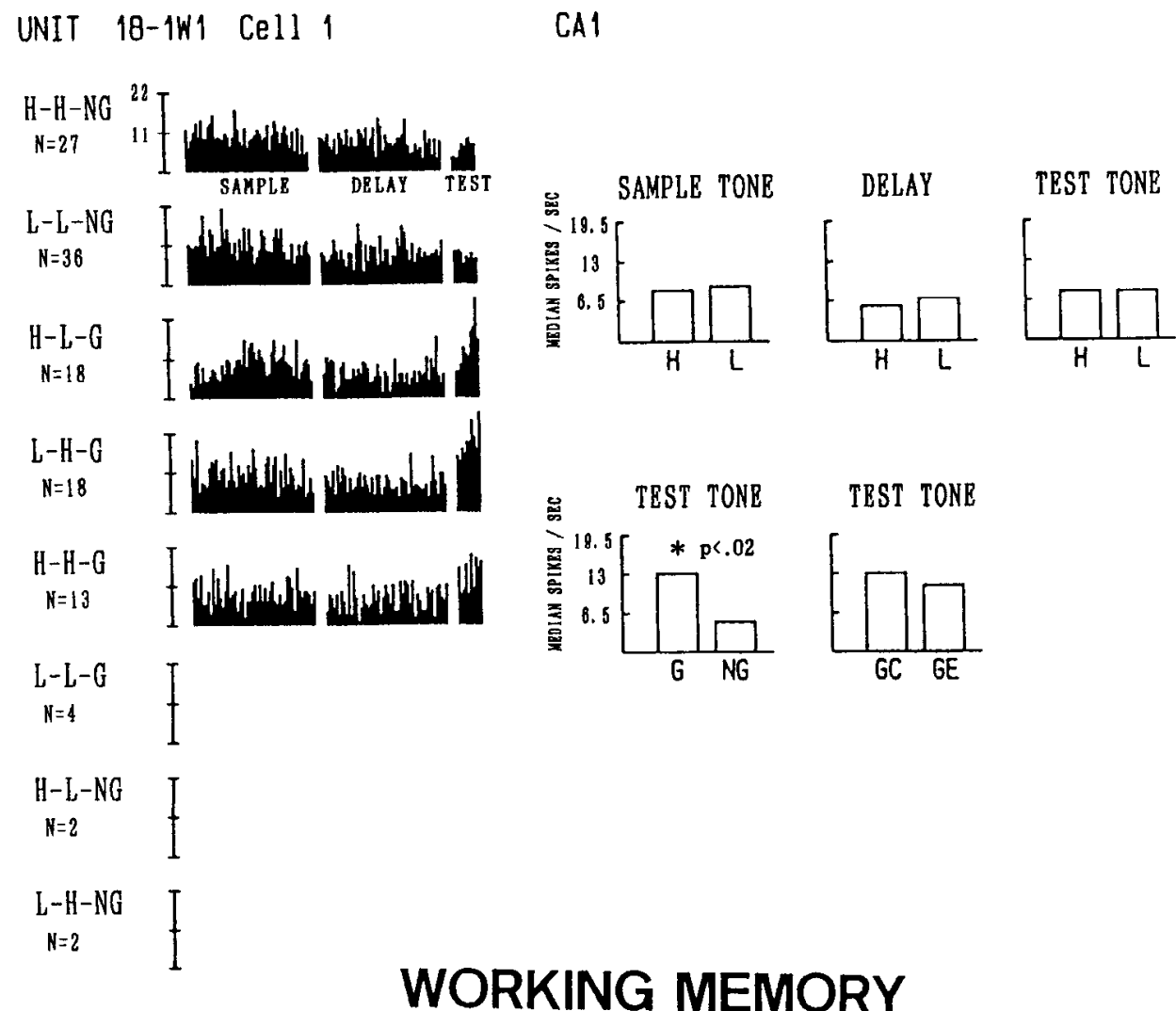

Figure 10. Firing rate histograms and bar graphs from a CAl unit showing motor correlates both in the WM and in the RM tasks. All parameters and symbols are as in Figure 3.
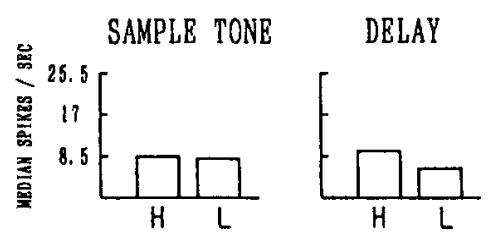

TEST TONE

$\begin{array}{ll}H-H-N G & 24 \\ N=0 & 12\end{array}$
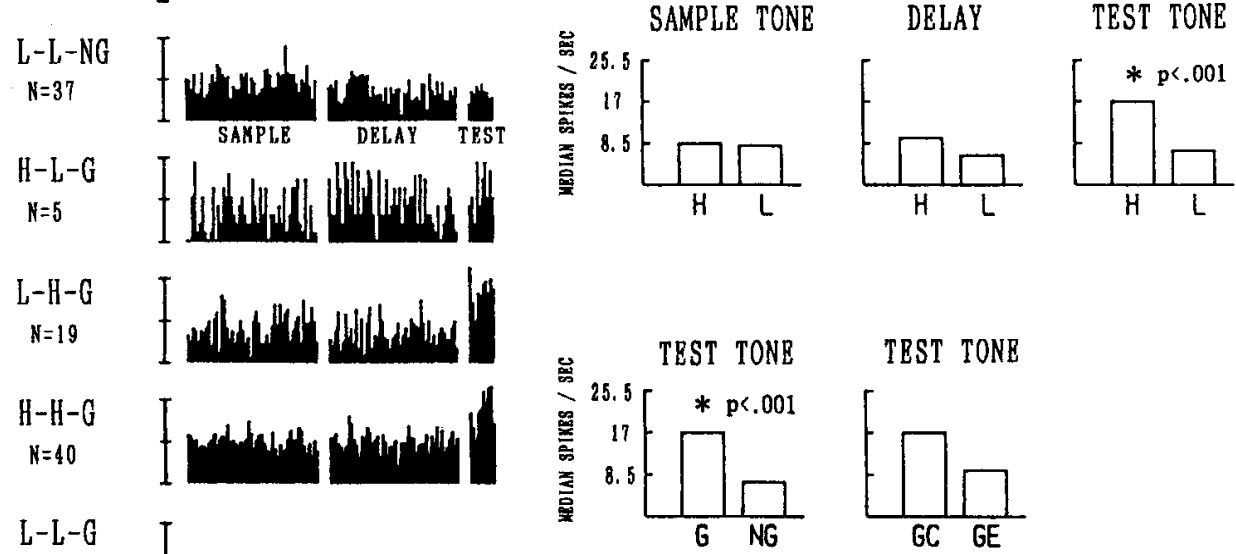

TEST TONE

$\mathrm{H}-\mathrm{H}-\mathrm{G}$

$N=4$

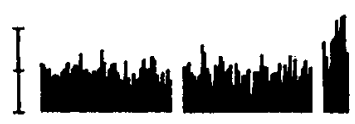

$\mathrm{L}-\mathrm{L}-\mathrm{G}$

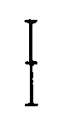

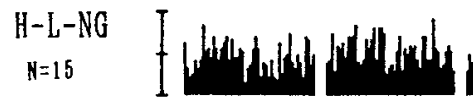

$\mathrm{L}-\mathrm{H}-\mathrm{NG}$

$N=1$

REFERENCE MEMORY 
UNIT 1-4W1 Cell 1
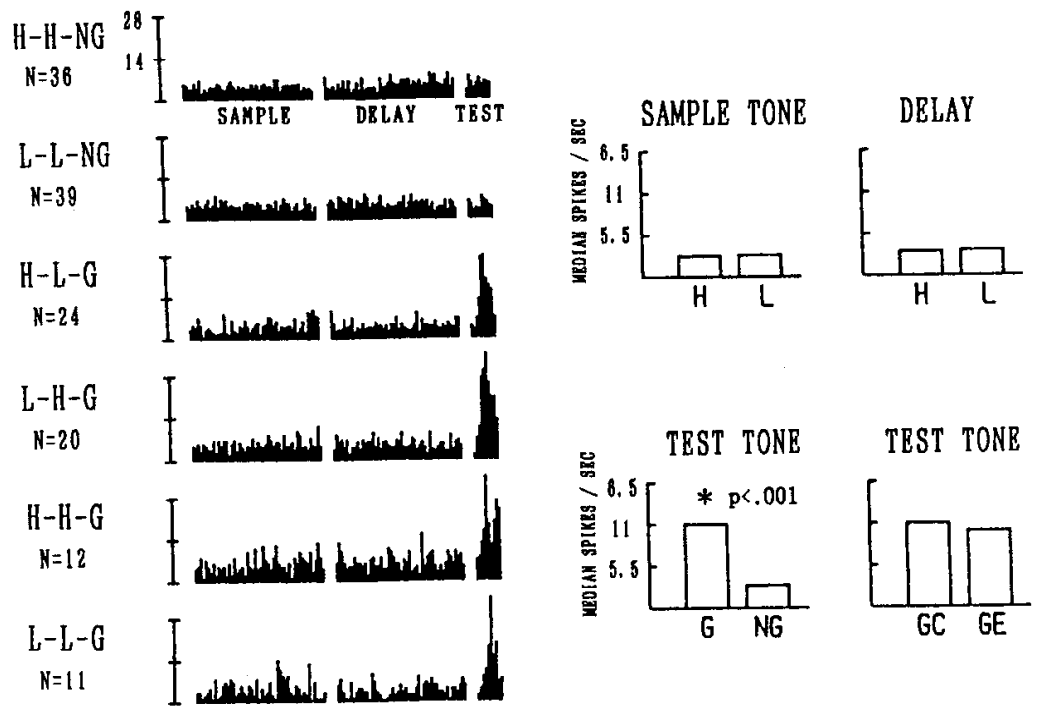

TEST TONE
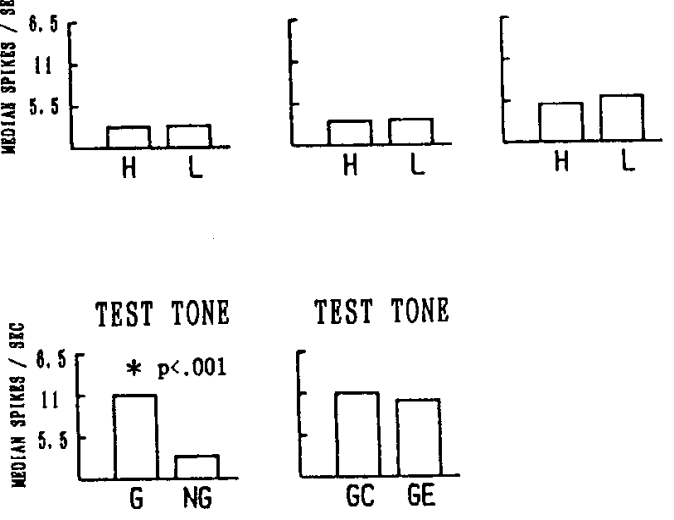

TEST TONB

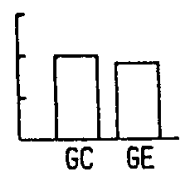

$\underset{H=3}{H-L-N G} \quad$

$L-H-N G$
$N=3$

WORKING MEMORY

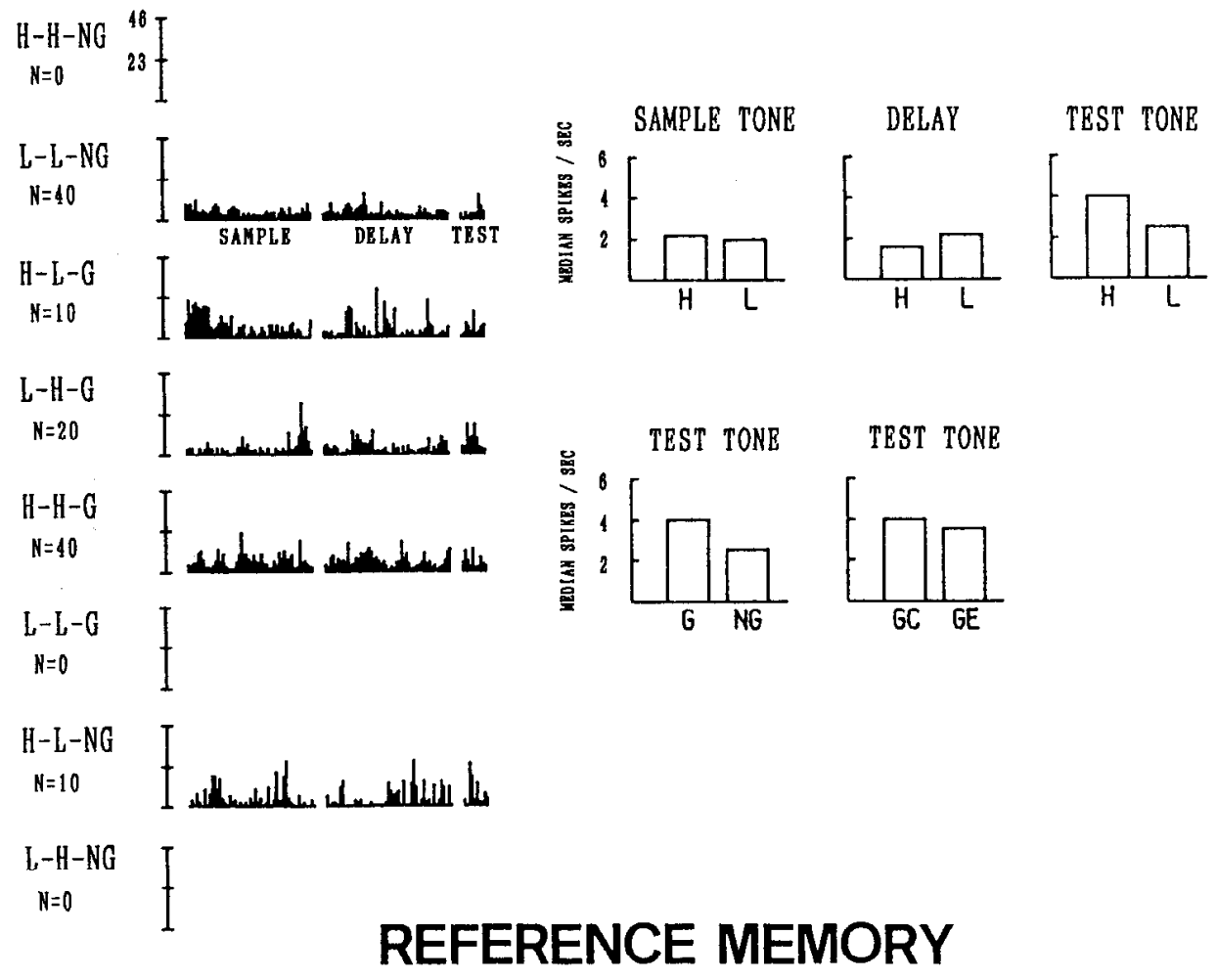

Figure 11. Firing rate histograms and bar graphs from a CA3 unit showing a motor correlate only in the WM task. All parameters and symbols are as in Figure 3. 
Table 1. Summary of proportions (\%) of units with sensory, sensoryretention, motor, comparison-motor, and multiple correlates in each of the four regions

$\mathrm{CAl}(41) \quad \mathrm{CA} 3(34) \quad \mathrm{DG}(43) \quad \mathrm{AC}(54)$

\begin{tabular}{lcccc}
\hline Sensory correlates & & & & \\
WM only & 7 & 12 & 12 & 11 \\
RM only & $41 \dagger$ & $41 \dagger$ & $53 \dagger$ & $37 \dagger$ \\
WM.RM different & 0 & 0 & 0 & 9 \\
WM-RM same & 0 & 0 & 0 & 40
\end{tabular}

Sensory-retention correlates

$\begin{array}{lcccc}\text { WM only } & 0 & 0 & 0 & 7^{*} \\ \text { RM only } & 22 \dagger & 24 \dagger & 35 \dagger & 37 \dagger \\ \text { WM RM different } & 0 & 0 & 0 & 0 \\ \text { WM RM same } & 0 & 0 & 0 & 11^{*}\end{array}$

Motor correlates

$\begin{array}{lcccc}\text { WM only } & 32^{*} \dagger & 35^{* \dagger} & 37^{* \dagger} & 9 \\ \text { RM only } & 7 & 18 & 12 & 7 \\ \text { WM } \cdot \text { RM different } & 0 & 0 & 0 & 0 \\ \text { WM-RM same } & 29 * \dagger & 32^{* \dagger} & 30^{* \dagger} & 9\end{array}$

Comparison-motor correlates

$\begin{array}{lcccc}\text { WM only } & 24^{*} \dagger & 21^{*} \dagger & 0 & 4 \\ \text { RM only } & 7 & 9 & 5 & 9 \\ \text { WM-RM different } & 0 & 0 & 0 & 0 \\ \text { WM-RM same } & 0 & 0 & 0 & 0\end{array}$

Multiple correlates

$\begin{array}{lcccc}\text { WM only } & 0 & 6 & 5 & 9 \\ \text { RM only } & 20 \dagger & 24 \dagger & 21 \dagger & 17 \dagger \\ \text { WM RM different } & 0 & 0 & 0 & 13^{*} \\ \text { WM RM same } & 0 & 0 & 0 & 0\end{array}$

WM only, units showing the corrclates only in the WM task; RM only, units showing the correlates only in the RM task; WM.RM different, units showing difference of the correlates between the WM and RM tasks; WM-RM same, units showing same of the correlates in the WM and RM tasks. Numbers in parentheses are the total units recorded.

* A statistically significant difference among the regions.

† A statistically significant difference among WM only, RM only, WM $\cdot$ RM different, and WM·RM same.

\section{Discussion}

Information processing by a single neuron and by groups of neurons

The proportions of the units with sensory, sensory-retention, motor, and comparison-motor correlates showed that there were some neurons underlying only one type of memory, WM or RM. This result suggests that a neuron is involved in sensory discrimination, retention, motor control, and/or comparison for only one type of memory. On the other hand, the proportions of the units with sensory, sensory-retention, and motor correlates also showed that there were some neurons that were related to both WM and RM in different or similar ways. This suggests that a neuron is involved in sensory discrimination, retention, and/or motor control for both types of memory.

Both the single neuron doctrine (Barlow, 1972) and the theory of cell assembly (Hebb, 1949) find some support in the above results. The finding that some neurons are involved in only one type of memory is consistent with the single neuron doctrine, regarding the neuron as the basic processor for only one type of memory. In a strict sense, however, the present study alone does not support the single neuron doctrine, because only two

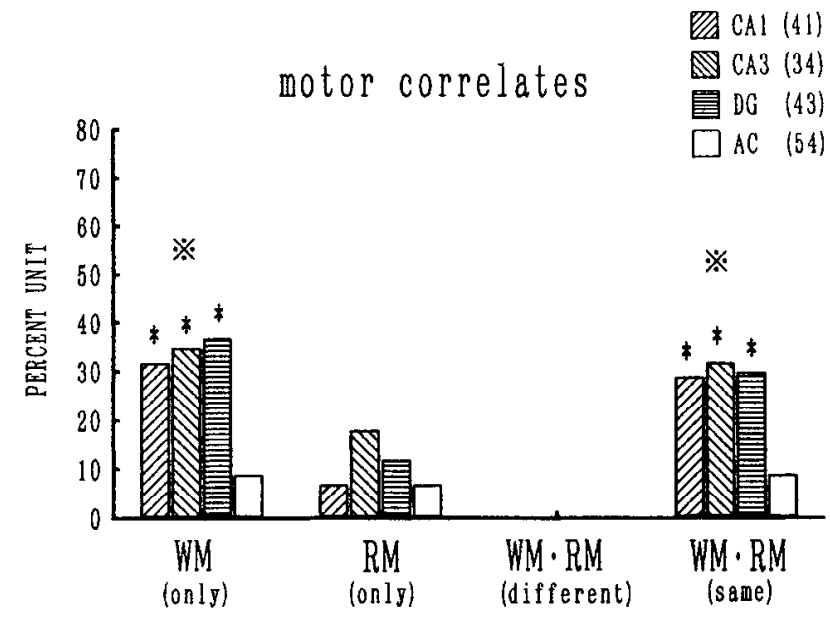

Figure 12. Proportions of the units with motor correlates in the four regions. All parameters and symbols are as in Figure 6.

types of memory, WM and RM, were employed and compared. Other types of memory, for example, some form of nondeclarative memory, should also be tested. Moreover, some recent studies have shown that the activity of individual neurons is not uniquely correlated with behavioral functions, but are flexible across different behavioral contexts (E. Ahissar et al., 1992; Montgomery et al., 1992).

The finding that some neurons are involved in both types of memory suggests that each neuron is just one of many neurons comprising cell assemblies for more than one type of memory. The neurons that participate in one cell assembly are thought to overlap considerably with other cell assemblies, implying that the average single neuron belongs to many assemblies (Palm, 1982). Therefore, any given neuron should underlie different types of memory. Other recent studies have shown correlated activity and flexible interactions between neurons that were recorded from monkeys performing memory tasks (E. Ahissar et al., 1992; M. Ahissar et al., 1992). Those interactions among neurons support the existence of cell assemblies for information processing of the memory. If cell assemblies are thought to be large or small groups of neurons with flexible functional interactions among them (Palm, 1990), there could be "neural codes" for memory, which are realized in interacted neuronal networks (Abeles, 1988; Gerstein et al., 1989).

The present results also showed that there are units with multiple correlates that underlie both sensory-related (sensory discrimination and retention) and motor-related (comparison and motor control) functions in a memory situation. This result supports the cell assembly theory, but not the single neuron doctrine which predicts that a behavioral function is uniquely encoded by individual neurons. The cell assembly theory expects a neuron to be a member of several assemblies, each of which has different functions in memory. A recent study (Montgomery et al., 1992) has also shown that some units from the motor cortex have correlates with several behavioral events within a single behavioral task; those findings suggest the representation of behavioral functions by groups of neurons.

\section{Functional dissociation of working and reference memory}

In the results from the units with sensory, sensory-retention, and multiple correlates, the proportions of the units with those correlates only in the RM task were larger than those only in 
UNIT 11-4W1 Cell 1

CA3

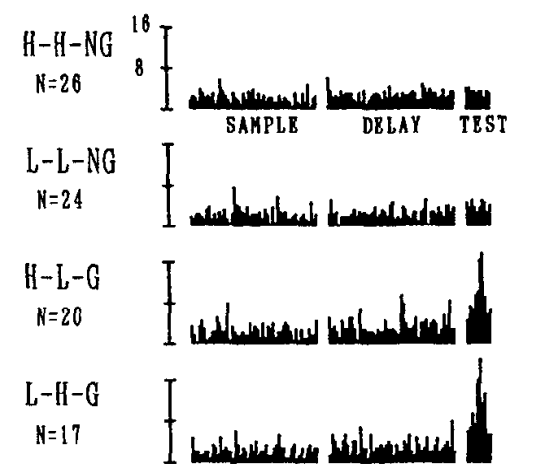

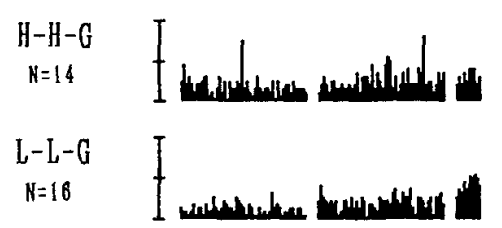

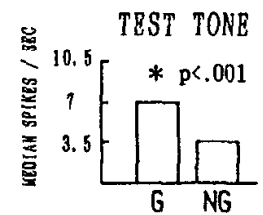

TEST TONE

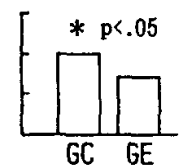

$H-L-N G$
$N=0$

L-H-NG

$H=3$

\section{WORKING MEMORY}

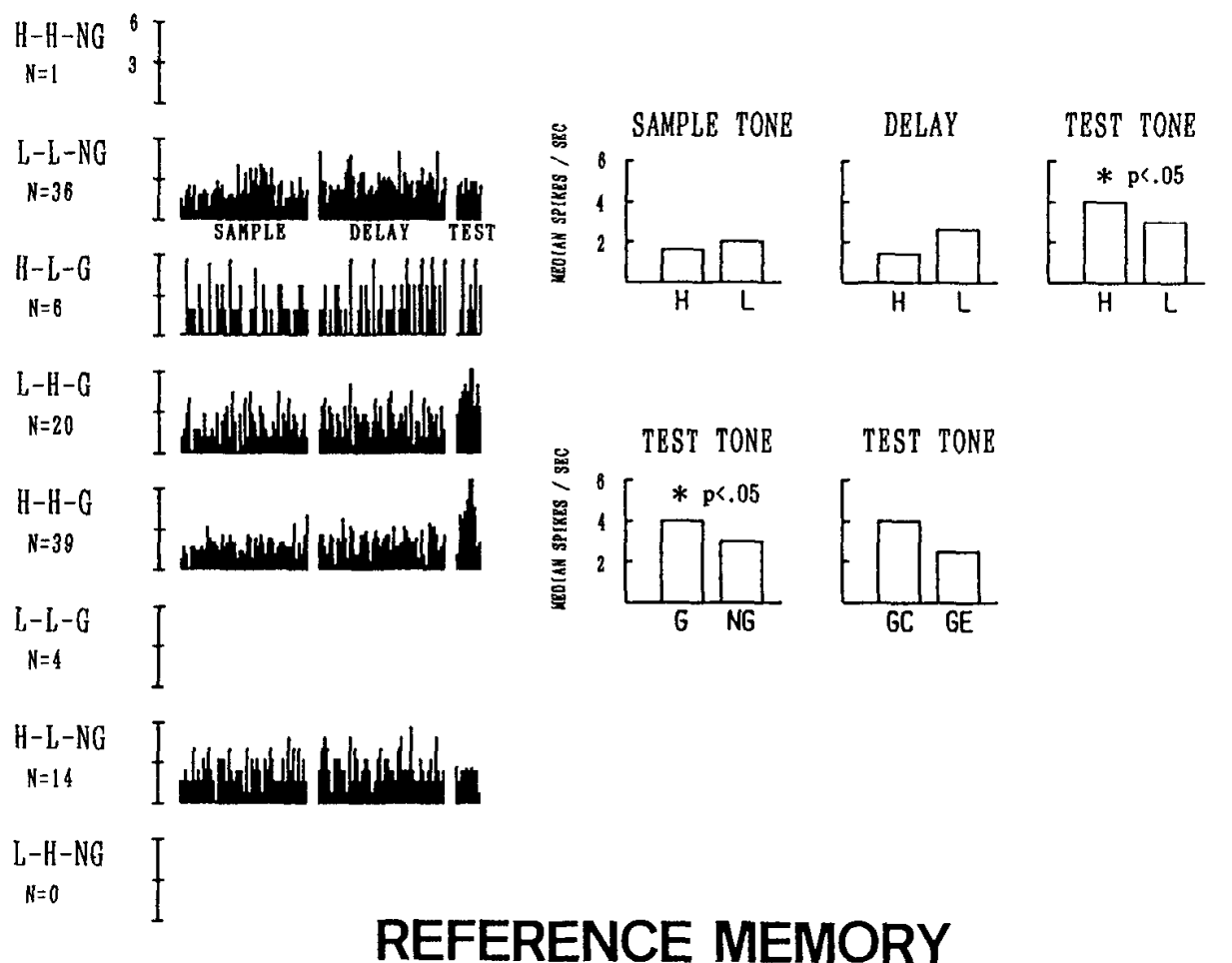

Figure 13. Firing rate histograms and bar graphs from a CA3 unit showing a comparison-motor correlate only in the WM task. All parameters and symbols are as in Figure 3. 


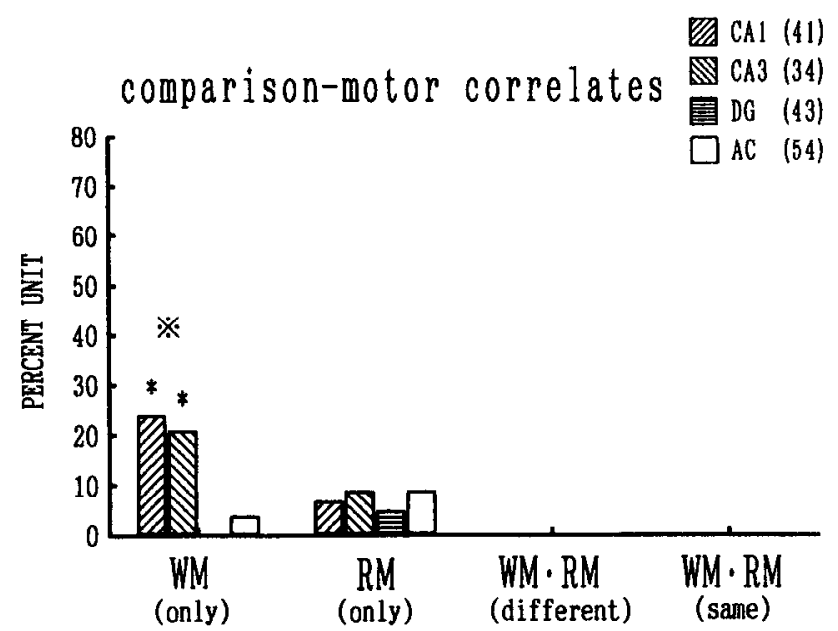

Figure 14. Proportions of the units with comparison-motor correlates in the four regions. All parameters and symbols are as in Figure 6.

the WM task. This suggests that more neurons are related to sensory discrimination, retention, and sensory-motor interactions for RM than for WM. By definition, WM is temporally changing and must be frequently set and reset, whereas RM is long-term and temporally constant, thus allowing for associations with other information stored in long-term RM (e.g., Olton, 1987). It could thercfore be expected that more neurons would be involved in RM to make it temporally stable and extensive enough for associative functions. This could be the reason why brain lesions, especially to hippocampal regions, sometimes disrupt RM less severely than WM (e.g., Olton and Feustle, 1981).

The large number of units with sensory-retention correlates only in the RM lask is difficult to understand, because the RM task does not require the rat to remember the sample tone during the delay period. One possible interpretation is that the sensoryretention correlates in the RM task might reflect a lasting activation of RM for the differential significance between the tones throughout the task, which consists of continuity of the tone and delay periods. Any nonmemory or general processes, for example, attention or motivation, cannot explain the differential activity of the units with sensory-retention correlates.

\section{Unique functions of the auditory cortex}

The units with sensory correlates showed that the AC alone had units with the same sensory correlates both in the WM and in the RM tasks. Those AC units did not include units that showed, after the tasks, differential stimulus-elicited activation similar to the sensory correlates they had during the memory tasks. Therefore, the same and common sensory correlates of the AC units reflect not simple sensory functions, but task-related mnemonic functions and sensory discrimination for both WM and RM. The AC alone also had units with different sensory correlates between the WM and the RM tasks. This surely represents not only general but also flexible functions of the $\mathrm{AC}$ neurons for sensory discrimination for both WM and RM.

The distribution of locations of the units with sensory correlates in the $\mathrm{AC}$ was not related to the known functional anatomy of AC (e.g., Sally and Kelly, 1988). This suggests that intrinsic properties of $\mathrm{AC}$ neurons shown in the strictly controlled anesthetized rat, narrowly tuned to frequencies of tones and more largely responsive to higher tones $(10-40 \mathrm{kHz}$ ) (Sally and Kelly, 1988), did not affect the sensory correlates of the AC units during freely moving performance of the tasks in this study. The training of the memory tasks for an extended period (morc than 1 month) might inducc lcarning-rclatcd plasticity in the neurons (Weinberger and Diamond, 1987, 1988; Weinberger et al., 1990) in broad areas of the AC. Those neurons are thought to become responsive to the tones used in the memory tasks during performance of the tasks. These responses are surely taskperformance dependent, because the neurons showed no specific responses to the tones at times when there was no memory task. A recent study showing receptive field plasticity in the AC during frequency discrimination training (Edeline and Weinberger, 1993) also indicates the flexibility of AC neurons for learned task performance.

The results from the units with sensory-retention correlates showed that the AC alone had units with sensory-retention correlates only in the WM task and it also had units with the same sensory-retention correlates in both of the memory tasks. This suggests that only the neurons in AC, not in the hippocampal regions, are again generally involved in sensory discrimination and retention for both of the different types of memory. Though a previous study (Sakurai, 1990b) has shown that neurons in $A C$ are involved in sensory discrimination and retention for WM, the present study indicates that $\mathrm{AC}$ neurons are involved in those processes not only for WM but also for RM. These functions of $\mathrm{AC}$ could be predicted from learning-induced changes of activity of AC neurons (Edeline et al., 1990) and learning-induced plasticity of receptive fields in $\mathrm{AC}$ (Weinberger et al., 1990; Edeline and Weinberger, 1993). Especially with regard to retention by $\mathrm{AC}$ neurons, the posttone facilitation of activity of $\mathrm{AC}$ units during the sequential presentation of tones (McKenna et al., 1989) might be related to a mechanism underlying the retention. An ablation study using monkeys (Colombo et al., 1990) showed severe impairment of auditory, but not visual, WM after lesions of the AC. It is therefore likely that $\mathrm{AC}$ is the most critical region that underlies the discrimination and retention of auditory stimuli both in WM and RM situations.

The results obtained from the units with multiple correlates show that the AC alone had units with different multiple correlates between the memory tasks. This suggests that the $A C$ neurons are again highly comprehensive and flexible for multiple sensory and motor interactions for both WM and RM. Some previous studies (Vaadia et al., 1982; Weinberger and Diamond, 1987) support the idea that AC neurons are involved in sensory-motor interactions for memory.

\section{Unique functions of the hippocampal regions}

The results from the units with sensory and sensory-retention correlates showed that hippocampal neurons were related to sensory discrimination for one type of memory, especially for $\mathrm{RM}$, and also to retention for RM. The hippocampal involvement in auditory discrimination could be predicted by several recent studies. For example, Tamura et al. (1992) demonstrated the monkey hippocampal neuron responses to several complex sensory stimuli during the discrimination learning. Moreover, hippocampal auditory evoked responses in the rat can be modulated with attention (Jirsa et al., 1992), and a gating mechanism in the hippocampus to auditory stimuli has also been reported (Luntz-Leybman et al., 1992). If the hippocampus underlies configural and/or cross-modality associations (e.g., Sutherland and Rudy, 1989), it is not strange that the hippocampal neurons 
UNIT 22-1W1 Cell 1
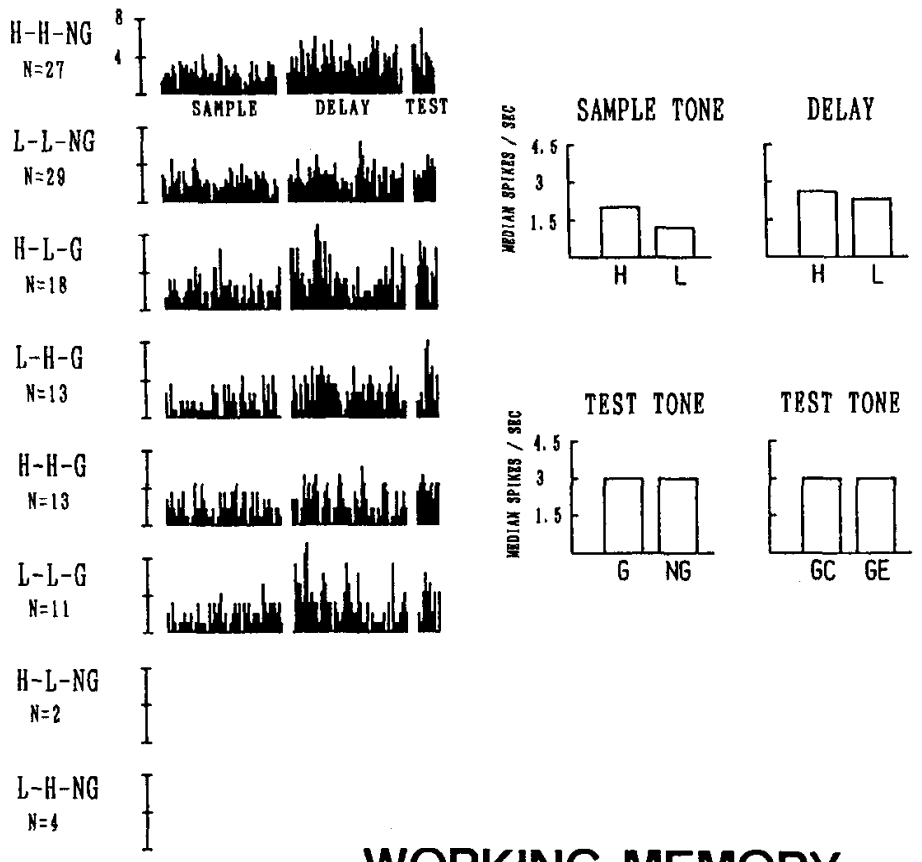

TEST TONE
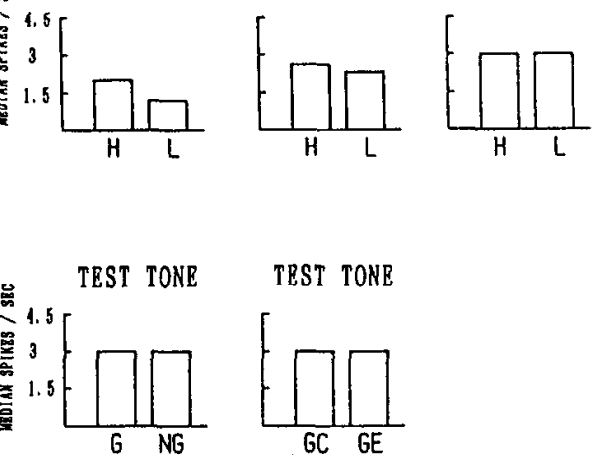

TEST TONB

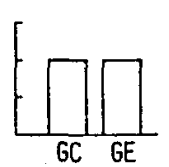

\section{WORKING MEMORY}

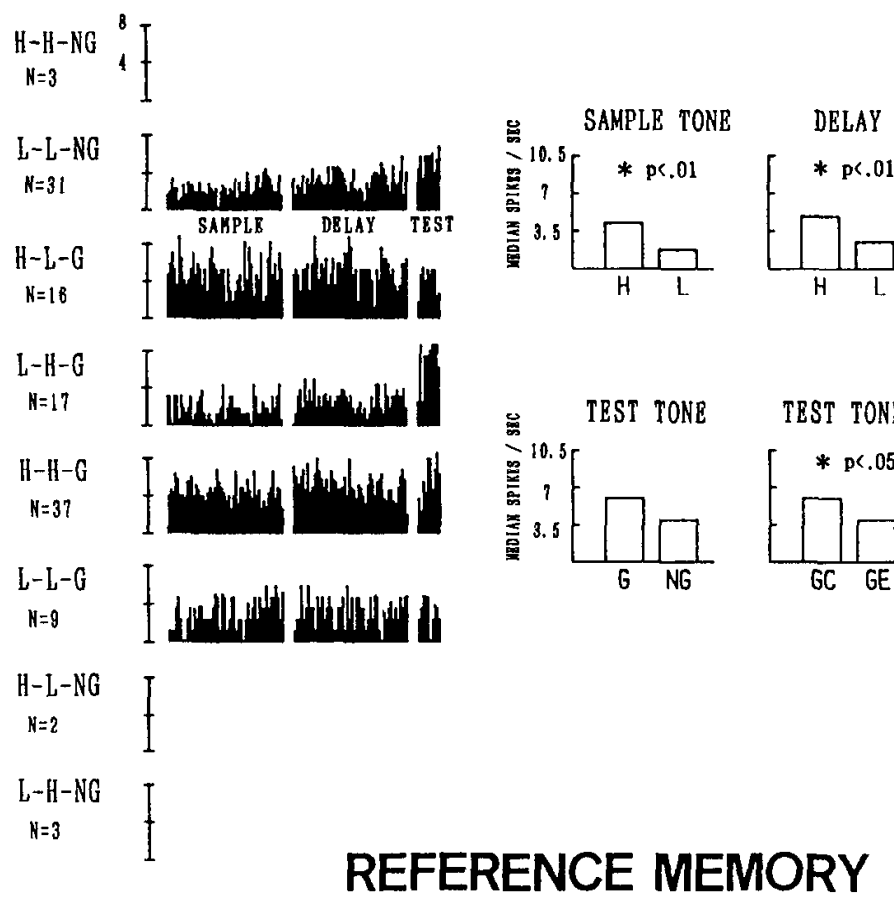

are involved in not only spatial (e.g., O'Keefe and Speakman, 1987) and/or olfactory (e.g., Eichenbaum et al., 1992) discrimination learning, but also auditory discrimination learning with retention for RM.

The units with motor correlates showed that the hippocampal CA1, CA3, and DG had more units with motor correlates only in the WM task than did the $A C$. Those hippocampal regions also had more units with the same motor correlates both in the WM and in the RM tasks. These results suggest that some hip-

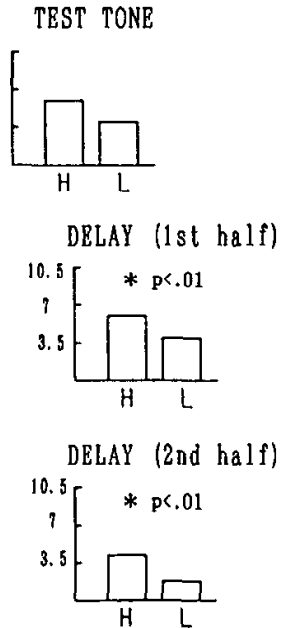

Figure 15. Firing rate histograms and bar graphs from a CA3 unit showing a multiple, sensory-retention and comparison-motor, correlate only in the RM task. All parameters and symbols are as in Figure 3.

pocampal neurons underlie motor control for only WM and other hippocampal neurons generally underlie motor control for both WM and RM. That is, the hippocampal neurons are more involved in motor control for WM than for RM, although they are also involved in motor control for RM. These functions in hippocampal regions could reconcile the working and the spatial memory hypotheses of the hippocampus in a manner similar to that suggested by Olton et al. (1989).

It was not possible to determine whether the unit activations 


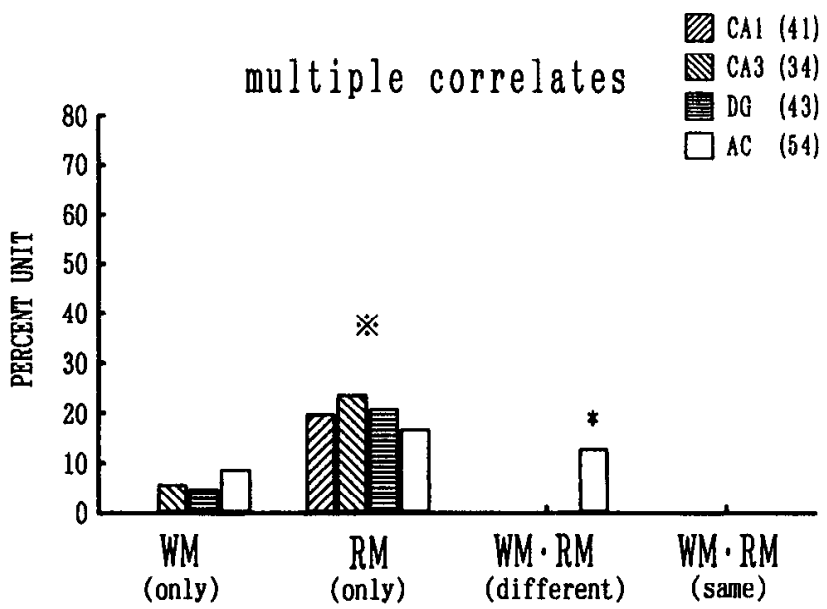

Figure 16. Proportions of the units with multiple correlates in the four regions. All parameters and symbols are as in Figure 6.

were related to simple motor responses in nontask situations, because the motor response in the memory tasks was not walking or sniffing but purposive nose-poking to press the panel. The hippocampal units with the same motor correlates in both of the memory tasks might therefore reflect simple motor functions independent of memory tasks. However, hippocampal involvement not in simple but in higher and mnemonic motor functions has been shown previously (i.e., Gabriel et al., 1986; Foster et al., 1989). It is consequently difficult to consider these hippocampal regions as simply a part of a primary motor system.

The results from the units with comparison-motor correlates showed that more CA1 and CA 3 units had the correlates only in the WM task than the other regions had. This suggests that the hippocampal CAl and CA3 are uniquely involved in processes of comparing the presented stimulus and retained WM. The result also showed that therc was no unique involvement of $\mathrm{CAl}$ and $\mathrm{CA} 3$ units in comparison processes for RM. These results are consistent with the result of a previous study (Sakurai, 1990a) that showed CA1 and CA3 involvement in comparisons for WM, and are supported by several other studies (Gabriel et al., 1986; Gray and Rawlins, 1986; Eichenbaum et al., 1987; Foster et al., 1987; Otto and Eichenbaum, 1992).

The above results indicate complex and broad functional aspects of the hippocampal neurons. For the sensory and sensoryretention functions, the hippocampal neurons are more related to RM. For the motor and comparison-motor functions, on the other hand, they are more related to WM. Therefore, the hippocampal neurons could function in WM, RM, and/or both of them in different manners according to the task situations demanded. This might explain the contradictory data of the hippocampal lesion studies, which showed impairment only in WM (e.g., Olton and Papas, 1979), only in RM (e.g., Leis et al., 1984), or in both WM and RM (e.g., Morris et al., 1986). Detailed examination of the task demands for sensory and motor functions and of the lesioned subfields within the hippocampus and related structures in such lesion studies is therefore needed.

The conclusions drawn from two previous studies (Sakurai, $1990 \mathrm{a}, \mathrm{b})$ using almost the same WM task as in the present study are the following: A sensory stimulus is discriminated and retained by the $\mathrm{AC}$, and then the hippocampal $\mathrm{CA} 1$ and CA3 regions compare the retained memory with the current stimulus and control the motor response. This flow of information is consistent with the conclusions from the present study using not only a WM task but also an RM task.

\section{References}

Abeles M (1988) Neural codes for higher brain functions. In: Information processing by the brain (Markowitsch HJ, ed), pp 225-238. Stuttgart: Huber.

Ahissar E, Vaadia E, Ahissar M, Bergman H, Arieli A, Abeles M (1992) Dependence of cortical plasticity on correlated activity of single neurons and on behavioral context. Science 257:1412-1414.

Ahissar M, Ahissar E, Bergman H, Vaadia E (1992) Encoding of sound-source location and movement: activity of single neurons and interactions between adjacent neurons in the monkey auditory cortex. J Neurophysiol 67:203-215.
Figure 17. Proportions of units which showed significant activation or inhibition, compared with their spontaneous firing rates, to the tones $(1-20 \mathrm{kHz})$ presented at times when there was no memory task. a frequency of the tone used in the memory tasks.
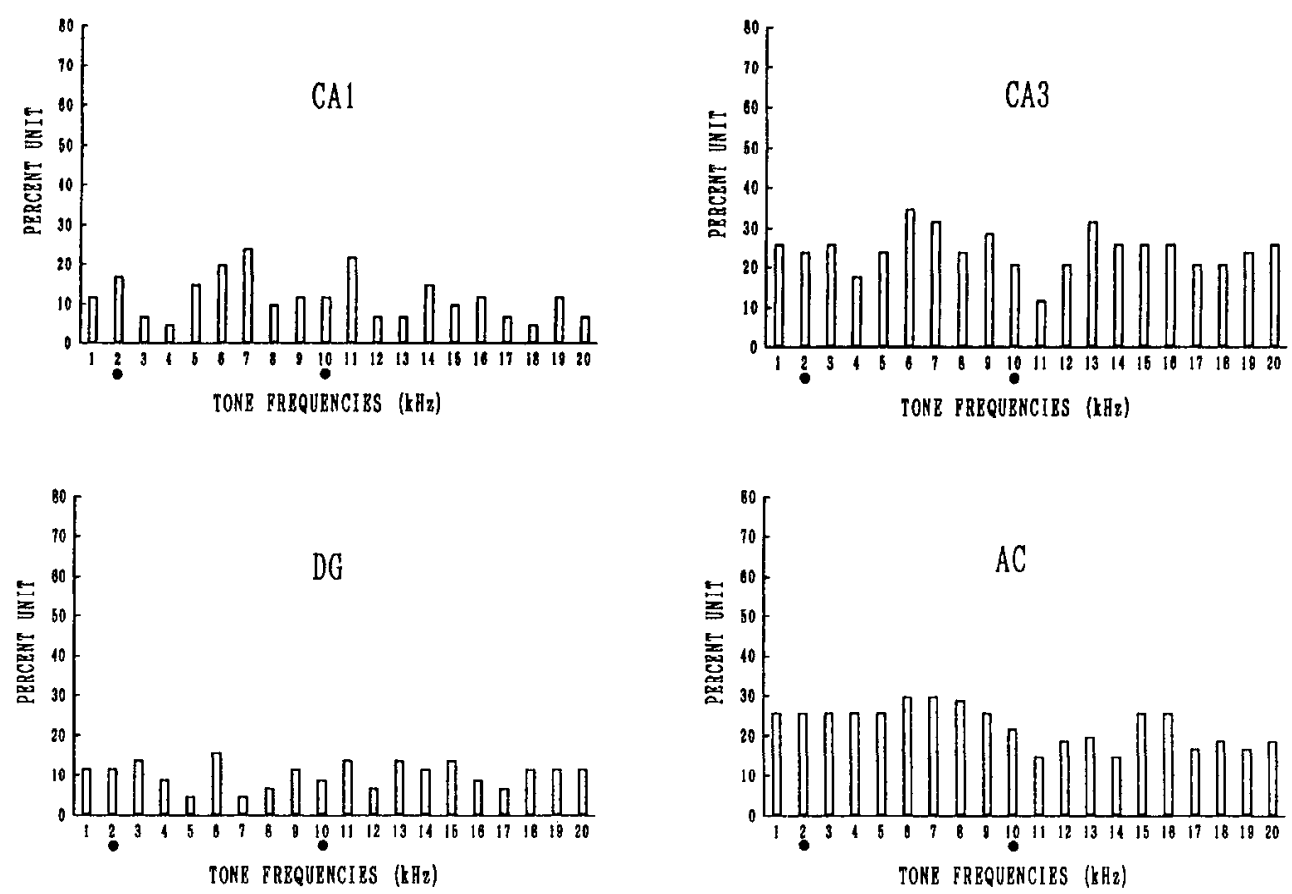
Barlow HB (1972) Single units and sensation: a doctrine for perceptual psychology? Perception 1:371-394.

Chan-Palay V, Kohler C (1989) The hippocampus: new vistas. New York: Liss.

Christian EP, Deadwyler SA (1986) Behavioral functions and hippocampal cell types: evidence for two non-overlapping populations in the rat. J Neurophysiol 55:331-348.

Colombo M, D'Amato MR, Rodman HR, Gross CG (1990) Auditory association cortex lesions impair auditory short-term memory in monkeys. Science 247:336-338.

D'Amato MR, Salmon DP (1982) Tune discrimination in monkeys (Cebus apella) and in rats. Anim Learn Behav 10:126-134.

Edeline JM, Weinberger NM (1993) Receptive field plasticity in the auditory cortex during frequency discrimination training: selective retuning independent of task difficulty. Behav Neurosci 107:82-103.

Edeline JM, Massioui NNE, Dutrieux G (1990) Frequency-specific cellular changes in the auditory system during acquisition and reversal of discriminative conditioning. Psychobiology 18:382-393.

Eichenbaum H, Kuperstein M, Fagan A, Nagode J (1987) Cue-sampling and goal-approach correlates of hippocampal unit activity in rats performing an odor-discrimination task. J Neurosci 7:716-732.

Eichenbaum H, Otto T, Cohen NJ (1992) The hippocampus: what does it do? Behav Neural Biol 57:2-36.

Foster TC, Christian EP, Hampson RE, Campbell KA, Deadwyler SA (1987) Sequential dependencies regulate sensory evoked responses of single units in the rat hippocampus. Brain Res 408:86-96.

Foster TC, Castro CA, McNaughton BL (1989) Spatial selectivity of rat hippocampal neurons: dependence on preparedness for movement. Science 244:1580-1582.

Gabriel M, Sparenborg SP, Stolar N (1986) An executive function of the hippocampus: pathway selection for thalamic neuronal significant code. In: The hippocampus, Vol 4 (Isaacson RL, Pribram KH, eds), pp 1-40. New York: Plenum.

Gerstein GL, Bedenbaugh P, Aertsen AMHJ (1989) Neuronal assemblies. IFEE Trans Biomed Eng 36:4-14

Gottlieb Y, Vaadia E, Abeles M (1989) Single unit activity in the auditory cortex of a monkey performing a short-term memory task. Exp Brain Res 74:139-148.

Gray JA, Rawlins JNP (1986) Comparator and buffer memory: an attempt to integrate two models of hippocampal function. In: The hippocampus, Vol 4 (Isaacson RL, Pribram KH, eds) pp 159-201. New York: Plenum.

Hebb DO (1949) The organization of behavior-a neuropsychological theory. New York: Wiley.

Honig WK (1978) Studies of working memory in the pigeon. In: Cognitive processes in animal behavior (Hulse SH, Fowler $\mathrm{H}$, Honig WK, eds), pp 211-248. Hillsdale, NJ: Erlbaum.

Jirsa R, Poc P, Radil T (1992) Hippocampal auditory evoked response threshold in the rat: behavioral modulation. Brain Res Bull 28:149153.

Leis T, Pallage V, Toniolo G, Will B (1984) Working memory theory of hippocampal function needs qualification. Behav Neural Biol 42 : 140-157.

Luntz-Leybman V, Bickford PC, Freeman R (1992) Cholinergic gating of response to auditory stimuli in rat hippocampus. Brain Res 587: 130-136.

McKenna TM, Weinberger NM, Diamond DM (1989) Responses of single auditory cortical neurons to tone sequences. Brain Res 481 : 142-153.

McNaughton BL, Barnes CA, Meltzer J, Sutherland RJ (1989) Hippocampal granule cells are necessary for normal spatial learning but not for spatially-selective pyramidal cell discharge. Exp Brain Res 76: $485-496$.

Montgomery EB Jr, Clare MH, Sahrmann S, Buchholz SR, Hibbard LS, Landau WM (1992) Neuronal multipotentiality: evidence for network representation of physiological function. Brain Res 580:4961.

Morris RGM, Hagan JJ, Rawlins JNP (1986) Allocentric spatial learning by hippocampectomised rats: a further test of the "spatial mapping" and "working memory" theories of hippocampal functions. Q J Exp Psychol 38B:365-395.

O'Keefe J, Speakman A (1987) Single unit activity in the rat hippocampus during a spatial memory task. Exp Brain Res 68:1-27.

Olton DS (1986) Hippocampal function and memory for temporal context. In: The hippocampus, Vol 4 (Isaacson RL, Pribram KH, eds), pp 281-298. New York: Plenum.

Olton DS (1987) Temporally constant and temporally changing spatial memory: single unit correlates in the hippocampus. In: Cognitive processes and spatial orientation in animal and man, Vol 2 (Ellen $P$, Thinus-Blanc C, eds), pp 16-27. Boston: Nijihoff.

Olton DS, Feustle WA (1981) Hippocampal function required for nonspatial working memory. Exp Brain Res 41:380-389.

Olton DS, Papas BC (1979) Spatial memory and hippocampal function. Neuropsychology 17:669-682.

Olton DS, Wible CG, Pang K, Sakurai Y (1989) Hippocampal cells have mnemonic correlates as well as spatial ones. Psychobiology 17: 228-229.

Otto T, Eichenbaum H (1992) Neuronal activity in the hippocampus during delayed non-match to sample performance in rats: evidence for hippocampal processing in recognition memory. Hippocampus $2: 323-334$

Palm G (1982) Studies of brain functions, Vol 7, Neural assemblies. New York: Springer.

Palm G (1990) Cell assemblies as a guideline for brain research. Concepts Neurosci 1:133-147.

Paxinos G, Watson C (1986) The rat brain in stereotaxic coordinates, 2 d ed. Sydney: Academic.

Pontecorvo MJ (1983) Effects of proactive interference on rat's continuous nonmatching-to-sample performance. Anim Learn Behav 11: 356-366.

Sakurai Y (1987) Rat's auditory working memory tested by continuous nonmatching-to-sample performance. Psychobiology 15:277-281.

Sakurai Y (1990a) Hippocampal cells have behavioral correlates during the performance of an auditory working memory task in the rat. Behav Neurosci 104:251-261.

Sakurai Y (1990b) Cells in the rat auditory systems have sensory-delay correlates during the performance of an auditory working memory task. Behav Neurosci 104:856-868.

Sakurai Y (1992a) Auditory working and reference memory can be tested in a single situation of stimuli for the rat. Behav Brain Res 50: 193-195.

Sakurai Y (1992b) Rat's hippocampal units have behavioral correlates during the performance of auditory working and reference memory tasks. Soc Neurosci Abstr 18:1065.

Sally SL, Kelly JB (1988) Organization of auditory cortex in the albino rat: sound frequency. J Neurophysiol 59:1627-1638.

Sasaki K, Ono T, Nishino H, Fukuda M, Muramoto K (1983) A method for long-term artifact-free recording of single unit activily in freely moving, eating and drinking animals. J Neurosci Methods 7:4347.

Siegel S (1956) Nonparametric statistics: for the behavioral sciences. Tokyo: McGraw-Hill

Squire LR (1987) Memory and brain. New York: Oxford UP.

Sutherland RJ, Rudy JW (1989) Configural association theory: the role of the hippocampal formation in learning, memory, and amnesia. Psychobiology 17:129-144.

Tamura R, Ono T, Fukuda M, Nishijo H (1992) Monkey hippocampal neuron responses to complex sensory stimulation during object discrimination. Hippocampus 2:287-306.

Tulving E (1972) Episodic and semantic memory. In: Organization of memory (Tulving E, Donaldson W, eds), pp 381-403. New York: Academic.

Vaadia E, Gottlieb Y, Abeles M (1982) Single-unit activity related to sensorimotor association in auditory cortex of a monkey. J Neurophysiol 48:1201-1213.

Weinberger NM, Diamond DM (1987) Physiological plasticity in auditory cortex: rapid induction by learning. Prog Neurobiol 29:1-55.

Weinberger NM, Diamond DM (1988) Dynamic modulation of the auditory system by associative learning. In: Auditory function: neurobiological bases of hearing (F.delman GM, Gall WF, Cowan WM, eds), pp 485-512. New York: Wiley.

Weinberger NM, Ashe JH, Metherate R, McKenna TM, Diamond DM, Bakin J (1990) Retuning auditory cortex by learning: a preliminary model of receptive field plasticity. Concepts Neurosci 1:91-132.

Wible CG, Findling RL, Shapiro M, Lang EJ, Crane S, Olton DS (1986) Mnemonic correlates of unit activity in the hippocampus. Brain Res 399:97-110. 